\title{
Annual Reversal of the Equatorial Intermediate Current in the Pacific: Observations and Model Diagnostics
}

\author{
Frédéric Marin, Elodie Kestenare, Thierry Delcroix, FAbien Durand, \\ SOPHIE CRAVATTE, AND GÉRARD ELDIN \\ Université de Toulouse, UPS (OMP-PCA), and IRD, LEGOS, Toulouse, France \\ ROMAIN BOURDALLÉ-BADIE \\ GIP Mercator Océan, Ramonville St. Agne, and CERFACS, Toulouse, France
}

(Manuscript received 21 July 2009, in final form 23 October 2009)

\begin{abstract}
A large reversal of zonal transport below the thermocline was observed over a period of 6 months in the western Pacific Ocean between $2^{\circ} \mathrm{S}$ and the equator [from $26.2 \mathrm{~Sv}\left(1 \mathrm{~Sv} \equiv 10^{6} \mathrm{~m}^{3} \mathrm{~s}^{-1}\right)$ eastward in October 1999 to 28.6 Sv westward in April 2000]. To document this reversal and assess its origin, an unprecedented collection of ADCP observations of zonal currents (2004-06), together with a realistic OGCM simulation of the tropical Pacific, was analyzed. The results of this study indicate that this reversal is the signature of intense annual variability in the subsurface zonal circulation at the equator, at the level of the Equatorial Intermediate Current (EIC) and the Lower Equatorial Intermediate Current (L-EIC). In this study, the EIC and the L-EIC are both shown to reverse seasonally to eastward currents in boreal spring (and winter for the L-EIC) over a large depth range extending from $300 \mathrm{~m}$ to at least $1200 \mathrm{~m}$. The peak-to-peak amplitude of the annual cycle of subthermocline zonal currents at $165^{\circ} \mathrm{E}$ in the model is $\sim 30 \mathrm{~cm} \mathrm{~s}^{-1}$ at the depth of the EIC, and $\sim 20 \mathrm{~cm} \mathrm{~s}^{-1}$ at the depth of the L-EIC, corresponding to a mass transport change as large as $\sim 100 \mathrm{~Sv}$ for the annual cycle of near-equatorial zonal transport integrated between $2^{\circ} \mathrm{S}$ and $2^{\circ} \mathrm{N}$ and between 410 - and $1340-\mathrm{m}$ depths. Zonal circulations on both sides of the equator (roughly within $2^{\circ}$ and $5.5^{\circ}$ in latitude) partially compensate for the large transport variability. The main characteristics of the annual variability of middepth modeled currents and subsurface temperature (e.g., zonal and vertical phase velocities, meridional structure) are consistent, in the OGCM simulation, with the presence, beneath the thermocline, of a vertically propagating equatorial Rossby wave forced by the westward-propagating component of the annual equatorial zonal wind stress. Interannual modulation of the annual variability in subthermocline equatorial transport is discussed.
\end{abstract}

\section{Introduction}

Surface circulation in the Pacific Ocean was described a few centuries ago from ship drift data recorded on board exploratory and commercial vessels (Black and Black 1853; Puls 1895). Since that time, many studies have been published describing the mean surface current system and, sometimes, its variability. Past studies have been based on hydrographic measurements and geostrophy,

Corresponding author address: Frédéric Marin, Laboratoire d'Etudes en Géophysique et Océanographie Spatiales (LEGOS), UMR 5566 CNES/CNRS/IRD/UPS, 14, Ave. Edouard Belin, 31400 Toulouse, France.

E-mail: frederic.marin@legos.obs-mip.fr
Sverdrup and Ekman relationships (Sverdrup et al. 1942; Reid 1961; Wyrtki 1974; Kessler and Taft 1987; Picaut and Tournier 1991), current meter moorings and drifting buoys (Reverdin et al. 1994), and sea level horizontal gradients computed from tide gauges or altimetry data (Bonjean and Lagerloef 2002; Sudre and Morrow 2008).

Subsurface circulation was documented much later than was surface circulation, with the main scientific investigations beginning in the middle of the twentieth century and obtained from oceanographic cruises conducted along cross-equatorial sections in the eastern (Cromwell et al. 1954; Knauss 1963; Hayes et al. 1983), central (Burkov and Ovchinnikov 1960; Wyrtki and Kilonsky 1984; Kessler and Taft 1987), and western (Rual 1969; Hisard and Rual 1970; Magnier et al. 1973; 


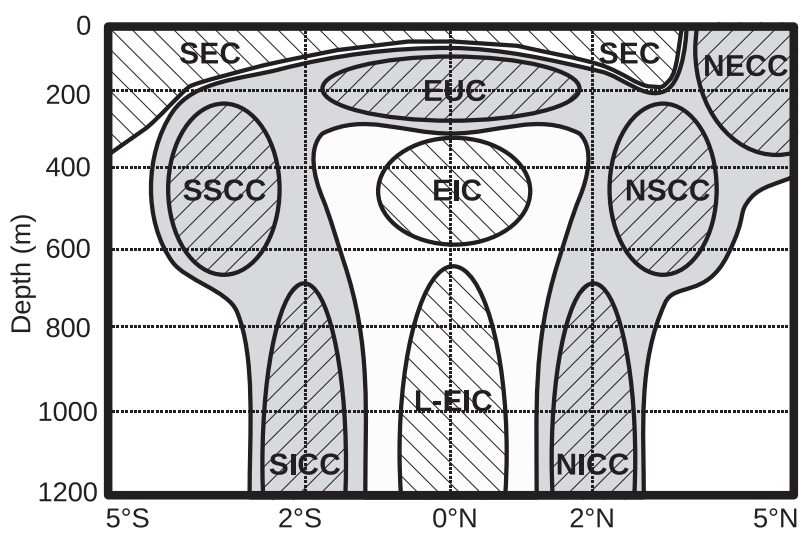

FIG. 1. A schematic of the structure of the equatorial current system in the western Pacific Ocean (near $165^{\circ} \mathrm{E}$ ). Shading denotes eastward flow. Right-upward-slanting hatched line is strong eastward flow. Left-upward-slanting hatched line is strong westward flow.

Delcroix et al. 1987; Gouriou and Toole 1993) tropical Pacific, as well as a few sections along the equator (Halpern 1980; Eldin et al. 1992).

In contrast to upper-ocean currents, few "deep" current measurements were conducted in the equatorial Pacific before the mid-1980s (e.g., Hisard and Rual 1970; Eriksen 1981; Leetmaa and Spain 1981; Firing 1987). The advent of ship-mounted and, most of all, lowered (attached to the rosette) acoustic Doppler current profiler (S-ADCP, L-ADCP) measurements considerably increased our knowledge of the three-dimensional circulation, especially for currents lying below the main thermocline (Firing et al. 1998; Rowe et al. 2000; Gouriou et al. 2006). With roots in past zonal and meridional measurements, Fig. 1 sketches the assumed meridional distribution for the mean structure of the equatorial current system in the western basin $\left(165^{\circ} \mathrm{E}\right)$, for which repetitive cruises were carried out over the past three to four decades (e.g., Delcroix et al. 1987; Gouriou and Toole 1993; Johnson et al. 2002). Noteworthy among the subthermocline currents is that the westward-flowing Equatorial Intermediate Current (EIC) is found beneath the Equatorial Undercurrent (EUC) and bounded meridionally by the North and South Subsurface Countercurrents (NSCC and SSCC). The EIC lies in the 250-500-m layer between approximately $2^{\circ} \mathrm{N}$ and $2^{\circ} \mathrm{S}$, and slopes downward to the west with a maximum velocity core of the order of 10-20 $\mathrm{cm} \mathrm{s}^{-1}$ (Hisard and Rual 1970; Firing 1987; Delcroix and Hénin 1988; Johnson et al. 2002; Gouriou et al. 2006).

At greater depths, a few observations suggest the presence (between 600- and 1200-m depths) of a distinct equatorial westward jet-the Lower Equatorial Intermediate Current (L-EIC) - that is bounded by two extraequatorial eastward jets: the South and North Intermediate Countercurrents (SICC and NICC). Still deeper, the equatorial zonal circulation is characterized by the presence of intense deep jets that flow alternately westward and eastward down to a 3000-m depth with typical vertical wavelengths of the order of $300 \mathrm{~m}$ and amplitudes of roughly 5-20 $\mathrm{cm} \mathrm{s}^{-1}$ (e.g., Eriksen 1981; Firing 1987).

While direct observations have provided some clues about the mean structures and variability of both the EIC and the L-EIC, present available observations are still too sparse to draw robust conclusions regarding their permanence and the causes of their variability. Sparse data are a major impediment since, for example, observations in the west-central equatorial Pacific $\left(165^{\circ} \mathrm{E}-\right.$ $180^{\circ}$ ) have given rise to large variability of the cumulated transports of both the EIC and the L-EIC between $2^{\circ} \mathrm{S}$ and the equator, from $26.2 \mathrm{~Sv}$ to the east in October 1999 to 28.6 Sv to the west in April 2000 (Gouriou et al. 2006), leading to a reversal of the net subthermocline zonal transport from approximately -50 to $+50 \mathrm{~Sv}$ in 6 months, using the assumption that both the EIC and the L-EIC are symmetrical with respect to the equator. As an alternative to the lack of in situ observations, in this manuscript we seek to describe and analyze the EIC and the L-EIC in the Pacific using a state-of-the-art, highresolution oceanic general circulation model (OGCM) validated against all available observations.

We address the following two main questions:

1) Are the large variations in observed subthermocline zonal transport a signature of seasonal, intraseasonal, or interannual variability?

2) What are the mechanisms responsible for these changes?

Section 2 describes the in situ data, the OGCM, and its validation. Section 3 analyzes the variability of the EIC and the L-EIC, while focusing on the dominant changes that were found to occur at the seasonal time scale. Section 4 then discusses the mechanisms responsible for these changes, while stressing the key effects of vertically propagating equatorial Rossby waves that are generated in the eastern part of the basin. In the last section of the manuscript, we present a discussion and conclusions.

\section{Data and model}

\section{a. In situ data}

As a first approximation toward documenting the EIC, we attempted to use annual and seasonal gridded fields of temperature and salinity profiles from the World 
Ocean Atlas (WOA05; Locarnini et al. 2006; Antonov et al. 2006), and we computed dynamic height anomalies and derived zonal geostrophic currents both on and off the equator using the method presented by Picaut and Tournier (1991). We tested various reference levels (from 500 to $4000 \mathrm{~m}$ ) for computing relative geostrophic currents. We also tested measured velocities averaged over various layers (of 50-100-m thickness in the upper $300 \mathrm{~m}$ ) as reference velocities to infer absolute geostrophic currents. Surprisingly, regardless of the tested reference levels or reference velocities, our computed geostrophic EIC was found to be unrealistic in terms of amplitude and vertical and meridional extensions when compared to direct measurements (see the following discussion), which likely reflects the sensitivity of geostrophic calculations at and near the equator to either the large-scale smoothing performed in the WOA05 or to inherent small dynamic height errors. For example, using finite differences to compute the second derivative of dynamic height anomalies over the $1^{\circ}$ meridional grid, an error of 1 dyn $\mathrm{cm}$ uncorrelated over the grid size gave an error of approximately $1.4 \mathrm{~m} \mathrm{~s}^{-1}$ for the equatorial geostrophic current. Therefore, inferring seasonal and annual means for the EIC structure from WOA05 temperature and salinity profiles and geostrophic relationships proved inconclusive.

To describe the EIC and the L-EIC, and to validate their structures in the model, we gathered a large number of direct current measurements. Among these, we used

1) mean sections of zonal currents along the equator and across $165^{\circ} \mathrm{E}$, obtained from a total of 172 S-ADCP sections carried out in the tropical Pacific from $143^{\circ} \mathrm{E}$ to $95^{\circ} \mathrm{W}$ during the 1990 s (Johnson et al. 2002);

2) numerous quasi-synoptic cross-equatorial and equatorial $75-\mathrm{kHz}$ S-ADCP sections collected in 2004 06 from the Joint Archive for Shipboard ADCP (JASADCP) from the University of Hawaii (see Table 1); and

3) L-ADCP measurements obtained during two cruises, FRONTALIS 2 (Ganachaud et al. 2006) and FRONTALIS 3 (Maes et al. 2006), carried out in the western Pacific during 2004 and 2005, respectively.

\section{b. Model}

We utilized the ORCA025 version of the Nucleus for European Modelling of the Ocean (NEMO) ocean general circulation model (OGCM) (Madec 2008). The model solves primitive equations on an Arakawa (1966) $\mathrm{C}$ grid over the global ocean, with $1 / 4^{\circ}$ horizontal resolution at the equator [tripolar ORCA grid; see Barnier et al.
(2006)] and 50 vertical levels on a $z$ grid. Vertical resolution varies with depth (i.e., $1 \mathrm{~m}$ at the surface, $20 \mathrm{~m}$ at $100 \mathrm{~m}, 110 \mathrm{~m}$ at $600 \mathrm{~m}$, and $450 \mathrm{~m}$ at $5000 \mathrm{~m}$ ). The model bathymetry results from an interpolation of the 2-minute gridded elevations/bathymetry for the world (ETOPO2V2g) dataset (information online at http:// www.ngdc.noaa.gov/mgg/fliers/01mgg04.html) onto the model grid. A partial step formulation (Barnier et al. 2006) was applied to the thickness of the bottom layer, and an energy- and enstrophy-conserving scheme was utilized (Arakawa and Lamb 1981). The vertical physics package was based on a prognostic equation for turbulent kinetic energy (Blanke and Delecluse 1993). A filtered free surface (Roullet and Madec 2000) was employed. Lateral diffusion was computed along isopycnal levels, with a Laplacian parameterization of $300 \mathrm{~m}^{2} \mathrm{~s}^{-1}$. Lateral viscosity was computed along horizontal levels with a biLaplacian parameterization of $-1.5 \times 10^{11} \mathrm{~m}^{2} \mathrm{~s}^{2}$. Viscosity was enhanced within $2.5^{\circ} \mathrm{S}-2.5^{\circ} \mathrm{N}$ by adding a Laplacian parameterization reaching $200 \mathrm{~m}^{2} \mathrm{~s}^{-1}$ at the equator. The model was spun up on 1 January 1999 from a state of rest using WOA05 temperature and salinity fields and run until April 2007. To exclude the numerical adjustment phase of the model during spinup, we considered the simulation only over the May 2001-April 2007 period. Subsurface isotherms were found to slightly and progressively deepen below the thermocline and near the equator over this period. Note that this deepening was not constant in latitude and was geostrophically related to a progressive, though moderate, intensification of the EIC and L-EIC at each longitude over the period of the simulation. We checked that this trend was essentially linear in time, and that no trend was visible in the seasonal cycle of the subthermocline currents and thermal structure, which is the main subject of this paper.

Atmospheric boundary conditions included surface fluxes of momentum, heat, and freshwater. The momentum and precipitation fluxes were prescribed; all of the other fluxes (e.g., heat and evaporation) were diagnosed from specified atmospheric variables using the bulk formula from the Coupled Large-Scale Ice Ocean (CLIO; Goosse et al. 2001). All atmospheric fields came from daily means computed from European Centre for Medium-Range Weather Forecasts (ECMWF) 6-h operational analyses (information online at http://www. ecmwf.int/products/forecasts/guide/). Model salinity was restored weakly to the WOA05 climatology at the sea surface. The large-scale component of the precipitation flux was nudged toward the Global Precipitation Climatology Project (GPCP; information online at http:// precip.gsfc.nasa.gov/) results using monthly data from $30^{\circ} \mathrm{N}$ to $30^{\circ} \mathrm{S}$. Monthly mean outputs were analyzed in this study. 
TABLE 1. Zonal subsurface transports between 300- and 600-m depths as observed at different longitudes from various cruises in the tropical Pacific Ocean from 2004 to 2006. Cruises are listed first by longitude and second by date for each longitude to facilitate comparison with Fig. 8. All transports were computed between $2^{\circ} \mathrm{S}$ and $2^{\circ} \mathrm{N}$, except for the data from FRONTALIS 2 (between $2^{\circ} \mathrm{S}$ and $1^{\circ} \mathrm{N}$ at $165^{\circ} \mathrm{E}$ and between $2^{\circ} \mathrm{S}$ and $1.5^{\circ} \mathrm{N}$ at $174^{\circ} \mathrm{E}$ ). S-ADCP data were used for all of the cruises except FRONTALIS 2 and FRONTALIS 3 , for which deeper-reaching L-ADCP observations were utilized. The names of the cruises, except FRONTALIS 2 and FRONTALIS 3 , are the same as those referenced in the Joint Archive for Shipboard ADCP (JASADCP) dataset (information online at http://ilikai.soest.hawaii.edu/ sadcp/index.html). All S-ADCP measurements extend deeper than $600 \mathrm{~m}$, except for the KA0601 cruise (140 Wanuary 2006), during which they were limited to the top $500 \mathrm{~m}$.

\begin{tabular}{|c|c|c|c|c|c|}
\hline \multirow[b]{2}{*}{ Cruise ID } & \multirow[b]{2}{*}{ Lon } & \multirow[b]{2}{*}{ Date } & \multirow[b]{2}{*}{ Obs (Sv) } & \multicolumn{2}{|c|}{ Model (Sv) } \\
\hline & & & & Monthly mean & Intramonthly std \\
\hline FRONTALIS 2 & $165^{\circ} \mathrm{E}$ & Apr 2004 & 3.2 & 4.6 & 7.5 \\
\hline FRONTALIS 3 & $165^{\circ} \mathrm{E}$ & May 2005 & -2.2 & 13.9 & 4.3 \\
\hline KA0404 & $165^{\circ} \mathrm{E}$ & Jul 2004 & -10.5 & -6.4 & 6.3 \\
\hline KA0504 & $165^{\circ} \mathrm{E}$ & Jul 2005 & 1.6 & -6.4 & 6.1 \\
\hline KA0408 & $165^{\circ} \mathrm{E}$ & Nov 2004 & -6.4 & -14.6 & 3.0 \\
\hline KA0507 & $165^{\circ} \mathrm{E}$ & Dec 2005 & -5.4 & -19.4 & 2.5 \\
\hline FRONTALIS 2 & $174^{\circ} \mathrm{E}$ & Apr 2004 & 13.4 & 5.5 & 8.3 \\
\hline KA0404 & $180^{\circ}$ & Aug 2004 & -18.2 & -15.8 & 4.4 \\
\hline KA0504 & $180^{\circ}$ & Aug 2005 & -12.7 & -16.3 & 6.2 \\
\hline KA0408 & $180^{\circ}$ & Dec 2004 & -11.5 & -5.3 & 4.1 \\
\hline KM0409BB & $170^{\circ} \mathrm{W}$ & Mar 2004 & 1.5 & 13.6 & 7.2 \\
\hline KM0507BB & $170^{\circ} \mathrm{W}$ & May 2005 & 5.8 & -4.6 & 14.0 \\
\hline KA0403 & $170^{\circ} \mathrm{W}$ & Jul 2004 & -18.3 & -21.5 & 5.5 \\
\hline KA0503B & $170^{\circ} \mathrm{W}$ & Jul 2005 & -4.4 & -12.8 & 4.7 \\
\hline KM0416BB & $170^{\circ} \mathrm{W}$ & Sep 2004 & -24.2 & -12.9 & 5.1 \\
\hline KA0407 & $170^{\circ} \mathrm{W}$ & Nov 2004 & -11.9 & -12.5 & 5.0 \\
\hline KA0403 & $155^{\circ} \mathrm{W}$ & Jun 2004 & -8.5 & -18.3 & 9.9 \\
\hline KA0503A & $155^{\circ} \mathrm{W}$ & Jun 2005 & -18.0 & -14.7 & 2.3 \\
\hline KA0506A & $155^{\circ} \mathrm{W}$ & Oct 2005 & -16.7 & -5.9 & 9.7 \\
\hline KA0407 & $155^{\circ} \mathrm{W}$ & Nov 2004 & -1.7 & -5.0 & 4.9 \\
\hline KA0507 & $155^{\circ} \mathrm{W}$ & Dec 2005 & 20.8 & -7.7 & 11.2 \\
\hline TN191_1NB & $151^{\circ} \mathrm{W}$ & Feb 2006 & 20.0 & 11.9 & 4.3 \\
\hline KA0601 & $140^{\circ} \mathrm{W}$ & Jan 2006 & 13.6 & 15.9 & 7.7 \\
\hline KA0402B & $140^{\circ} \mathrm{W}$ & May 2004 & -3.9 & -22.9 & 9.2 \\
\hline KA0405 & $140^{\circ} \mathrm{W}$ & Sep 2004 & -7.1 & -1.9 & 2.1 \\
\hline KA0505 & $140^{\circ} \mathrm{W}$ & Sep 2005 & -10.0 & -5.5 & 6.6 \\
\hline KA0601 & $125^{\circ} \mathrm{W}$ & Jan 2006 & -23.5 & 3.2 & 8.4 \\
\hline KA0402A & $125^{\circ} \mathrm{W}$ & May 2004 & 4.5 & -7.7 & 10.6 \\
\hline KA0405 & $125^{\circ} \mathrm{W}$ & Sep 2004 & 2.6 & 14.7 & 6.2 \\
\hline KA0505 & $125^{\circ} \mathrm{W}$ & Sep 2005 & 21.2 & 8.7 & 8.4 \\
\hline KA0401 & $110^{\circ} \mathrm{W}$ & Apr 2004 & 10.8 & 15.8 & 2.6 \\
\hline KA0602 & $110^{\circ} \mathrm{W}$ & Apr 2006 & -3.3 & -7.8 & 11.0 \\
\hline RB0506_LTA & $110^{\circ} \mathrm{W}$ & Nov 2005 & 12.1 & 13.5 & 3.7 \\
\hline KA0401 & $95^{\circ} \mathrm{W}$ & Apr 2004 & 16.7 & 20.5 & 4.4 \\
\hline
\end{tabular}

\section{Mean and seasonal variability of the observed and modeled EICs}

\section{a. Mean EIC}

Comparisons between the mean observed and modeled zonal current structures along the equator, from $95^{\circ} \mathrm{W}$ to $143^{\circ} \mathrm{E}$, and along $165^{\circ} \mathrm{E}$, from $5^{\circ} \mathrm{N}$ to $5^{\circ} \mathrm{S}$, are shown in Figs. 2 and 3. Note that the mean observed structure was obtained from the average of observations mostly collected in the 1990s (Johnson et al. 2002), while the mean modeled structure denotes the average of monthly means for the 2001-07 period. Along the equator, three zonal currents dominated the upper
$400 \mathrm{~m}$, showing similar properties in observations and in ORCA025 (Fig. 2), as follows:

1) near the surface, the South Equatorial Current (SEC) flows westward, with maximum velocities $\left(>25 \mathrm{~cm} \mathrm{~s}^{-1}\right)$ between $180^{\circ}$ and $120^{\circ} \mathrm{W}$

2) between 50- and 300-m depths, the EUC flows eastward, with velocities greater than $100 \mathrm{~cm} \mathrm{~s}^{-1}$ between $150^{\circ}$ and $120^{\circ} \mathrm{W}$, with two distinct cores of maximum velocities centered near $150^{\circ} \mathrm{E}$ and $130^{\circ} \mathrm{W}$; and

3) below $300 \mathrm{~m}$, westward velocities corresponding to the EIC are present with magnitudes of the order of $10 \mathrm{~cm} \mathrm{~s}^{-1}$. 

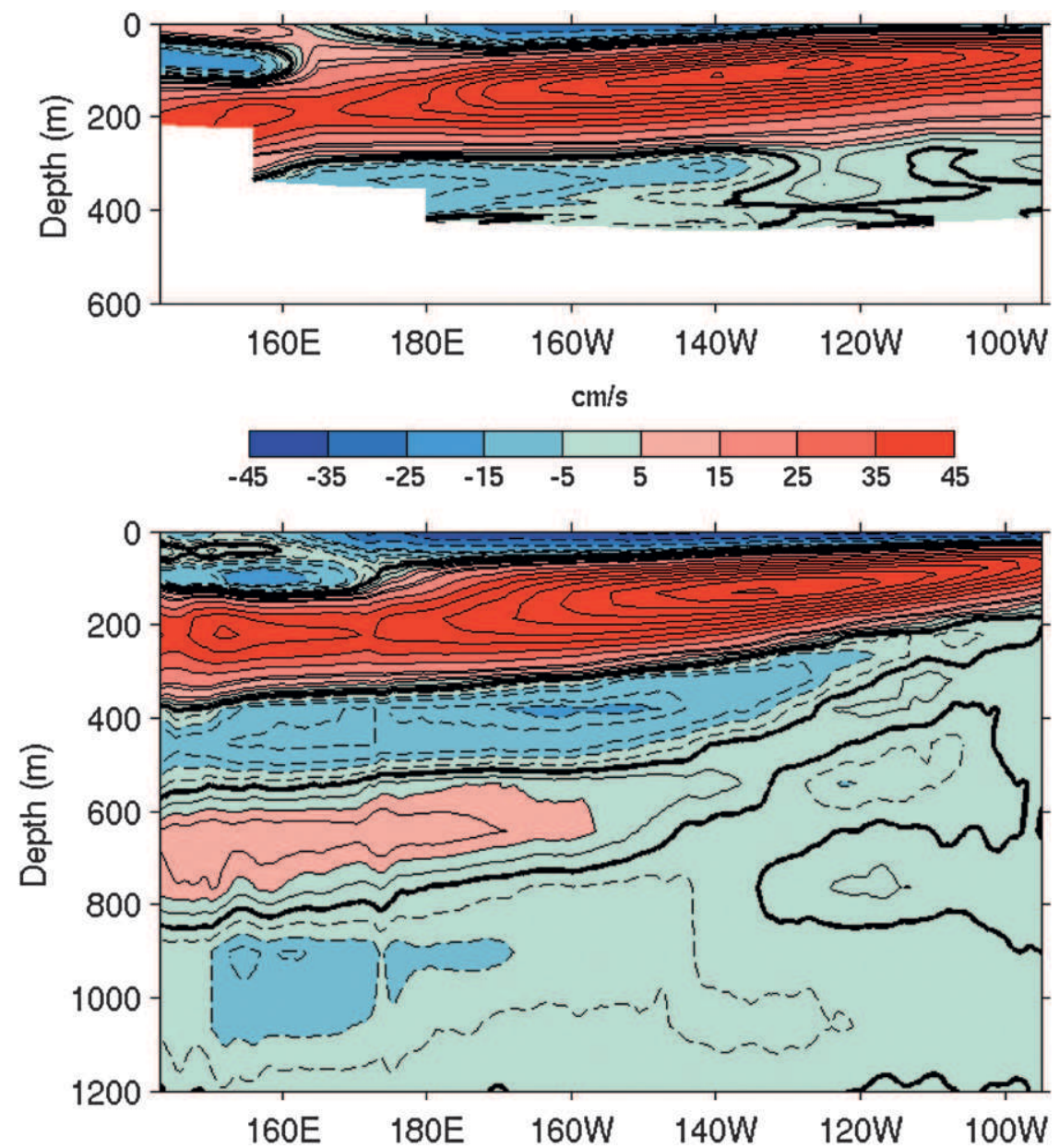

FIG. 2. Mean zonal sections of zonal currents along the equator from (top) S-ADCP observations by Johnson et al. (2002) and (bottom) the ORCA025 model. The contour interval is $10 \mathrm{~cm} \mathrm{~s}^{-1}$ for absolute velocities $>15 \mathrm{~cm} \mathrm{~s}^{-1}$ and is increased to $2.5 \mathrm{~cm} \mathrm{~s}^{-1}$ for velocities between -10 and $10 \mathrm{~cm} \mathrm{~s}^{-1}$. Positive values denote eastward currents. The boldface line is the zero isotach. The time average was performed over 172 sections carried out between June 1985 and December 2000 for S-ADCP observations and from 2001 to 2007 for ORCA025 outputs. The color bar is restricted to velocities between -45 and $+45 \mathrm{~cm} \mathrm{~s}^{-1}$.

The second relative maximum of westward velocities associated with the L-EIC is present in ORCA025 below $800 \mathrm{~m}$. The modeled L-EIC has velocities that are similar to the EIC between $150^{\circ} \mathrm{E}$ and $170^{\circ} \mathrm{W}$; however, it weakens more eastward, whereas the upper EIC exhibits maximum velocities $\left(>15 \mathrm{~cm} \mathrm{~s}^{-1}\right)$ between $170^{\circ}$ and $150^{\circ} \mathrm{W}$. The L-EIC is separated from the EIC in ORCA025 throughout the basin by an eastward current. The presence of such an eastward current in the observations is not obvious, even though it has been suggested from individual cruises in Delcroix and Hénin (1988, their Figs. 1 and 2), Gouriou and Toole (1993, their Fig. 3c), and Firing et al. (1998). Mean sections at $165^{\circ} \mathrm{E}$, computed by geostrophy (e.g., Firing et al. 1998; Gouriou et al. 2006), rather suggest that the EIC and L-EIC cores are separated by a minimum of westward current. Note the progressive eastward shoaling of subsurface currents in the model (from the EUC down to the lower EIC), which is also seen in the observations for the EUC and (though less obviously) for the EIC.

Meridional sections along $165^{\circ} \mathrm{E}$ (Fig. 3) show comparable latitudinal structures for the currents in the observations and in the model. Both the EIC and the L-EIC are equatorially trapped and do not extend poleward of $2^{\circ}$ in either hemisphere. The EIC is bordered on the north and south of the equator by eastward currents, centered near $3^{\circ} \mathrm{N}$ and $3^{\circ} \mathrm{S}$, and are known as the NSCC and the SSCC or Tsuchiya jets (Rowe et al. 2000). Both the NSCC and the SSCC prove to be less intense in ORCA025 $\left(<10 \mathrm{~cm} \mathrm{~s}^{-1}\right)$ than in the observations $\left(>15 \mathrm{~cm} \mathrm{~s}^{-1}\right)$, but 


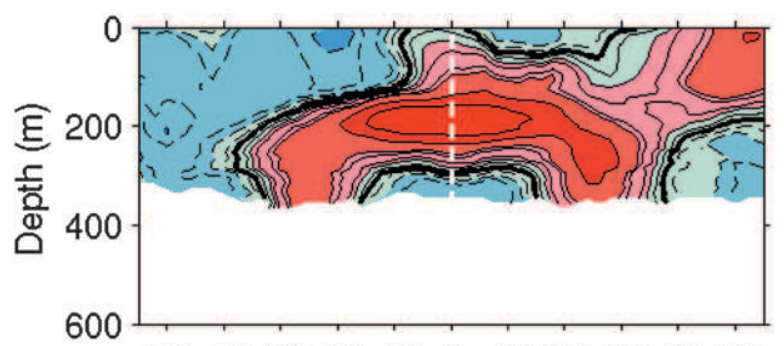

$5 S$ 4S $3 S$ 2S $1 S \quad 0 \quad 1 N 2 N$ 3N $4 \mathrm{~N} 5 \mathrm{~N}$

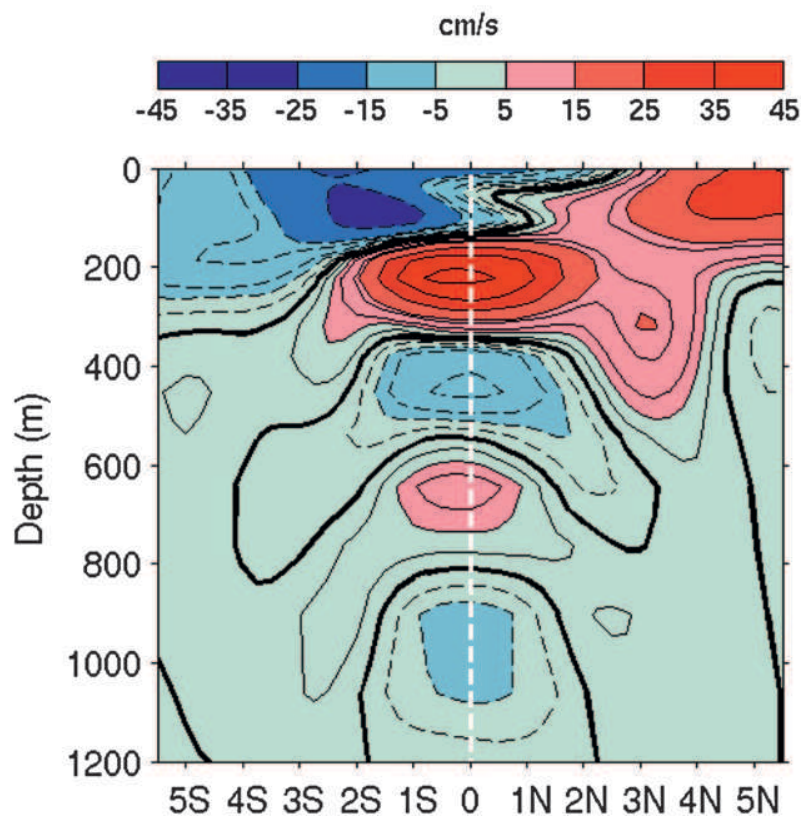

FIG. 3. As in Fig. 2, but along $165^{\circ} \mathrm{E}$.

the stronger magnitude of the NSCC, as compared to the SSCC, is common to ORCA025 and to the observations. Corresponding standard deviations (not shown here) near the equator are larger between 300 and $500 \mathrm{~m}$ $\left(>12.5 \mathrm{~cm} \mathrm{~s}^{-1}\right)$ than deeper, indicating that the EIC is more variable in time than the L-EIC in the model.

At greater depths (below $400 \mathrm{~m}$ ), observational studies (e.g., Firing 1987, 1988; Firing et al. 1998; Gouriou et al. 2006) have revealed the presence of subsurface eastward currents (SICC and NICC) at $2^{\circ} \mathrm{S}$ and $2^{\circ} \mathrm{N}$ that border the L-EIC in the western-central Pacific (see also Fig. 1). These currents are not present in the time-averaged meridional section along $165^{\circ} \mathrm{E}$ in the model. Also of note is the absence of deep jets in the model (not shown) beneath the L-EIC. This may be in part due to the vertical resolution in the model (from $150 \mathrm{~m}$ at $1000 \mathrm{~m}$ to $350 \mathrm{~m}$ at $3000 \mathrm{~m}$ ), which is too weak in comparison with the vertical scales of the jets $(\sim 300 \mathrm{~m})$.

\section{b. Seasonal cycle of the subthermocline currents}

Observations indicate that the EIC and the L-EIC are not permanent features of the subsurface circulation in the equatorial Pacific (e.g., Delcroix and Hénin 1988; Firing et al. 1998). Based on surface-to-bottom current measurements repeated at about 1-month intervals along $159^{\circ} \mathrm{W}$, from March 1982 to June 1983, Firing (1987) noted that eastward currents could episodically replace the EIC and the L-EIC, a feature that led him to conclude that the status of these currents was "nebulous." More recently, from L-ADCP measurements along $165^{\circ} \mathrm{E}$ and along the equator, Gouriou et al. (2006) saw evidence for an intense time variability in equatorial subthermocline currents, with westward velocities $\left(>20 \mathrm{~cm} \mathrm{~s}^{-1}\right)$ at the equator in October 1999 reversing to eastward velocities $\left(>25 \mathrm{~cm} \mathrm{~s}^{-1}\right)$ in April 2000 over a large depth range extending from $300 \mathrm{~m}$ down to $1200 \mathrm{~m}$ (Fig. 4, top). Comparable reversals of subthermocline currents were simulated in ORCA025 between $3^{\circ} \mathrm{S}$ and $3^{\circ} \mathrm{N}$ during the same months of the year, for example, in October 2006 and April 2007 (Fig. 4, bottom). The reversal was present from $164^{\circ} \mathrm{E}$ to $180^{\circ}$ along the equator (Fig. 5) both in the observations and in ORCA025, and extended from $135^{\circ} \mathrm{E}$ to $160^{\circ} \mathrm{W}$ in the model (not shown). In ORCA025 (Fig. 5, bottom), both the EIC and the LEIC are strong in October 2006 (with westward velocities $>35 \mathrm{~cm} \mathrm{~s}^{-1}$ for the EIC and $>15 \mathrm{~cm} \mathrm{~s}^{-1}$ for the LEIC) and reverse into an eastward current in April 2007 (Fig. $5 b$ ). Between the EIC and the L-EIC (between 600- and 700 -m depths), zonal velocities were weak $\left(<5 \mathrm{~cm} \mathrm{~s}^{-1}\right)$ in October 2006 and were significantly reinforced in April 2007 to become strongly eastward $\left(>25 \mathrm{~cm} \mathrm{~s}^{-1}\right)$. Such a vertical structure cannot be unambiguously identified from the observations in 1999-2000 (Fig. 5, top), where the presence of high-frequency small-scale features along with the possible interannual variability of subsurface currents may complicate the picture.

The latitude-time diagram of the current seasonal anomalies (vertically averaged between 450 and $540 \mathrm{~m}$ ) at $165^{\circ} \mathrm{E}$ in ORCA025 (Fig. 6, left) shows that the EIC reversal was not specific to 2006-07, but occurred every year between $2^{\circ} \mathrm{S}$ and $2^{\circ} \mathrm{N}$ with comparable timing and magnitude from 2001 to 2007 . The finding provides strong numerical evidence that the EIC reversal observed in 1999-2000 in Gouriou et al. (2006) was not an isolated or extreme event, but was rather the signature of a large annual cycle in zonal velocities beneath the thermocline. EIC annual variability was associated with a clear annual variability in potential temperature in the equatorial band (Fig. 6, right). We determined that the monthly averaged zonal current anomalies associated with the EIC were predominantly in thermal wind balance with potential temperature anomalies in ORCA025, therefore demonstrating that the EIC was essentially geostrophic at seasonal to interannual time scales (not shown here). 

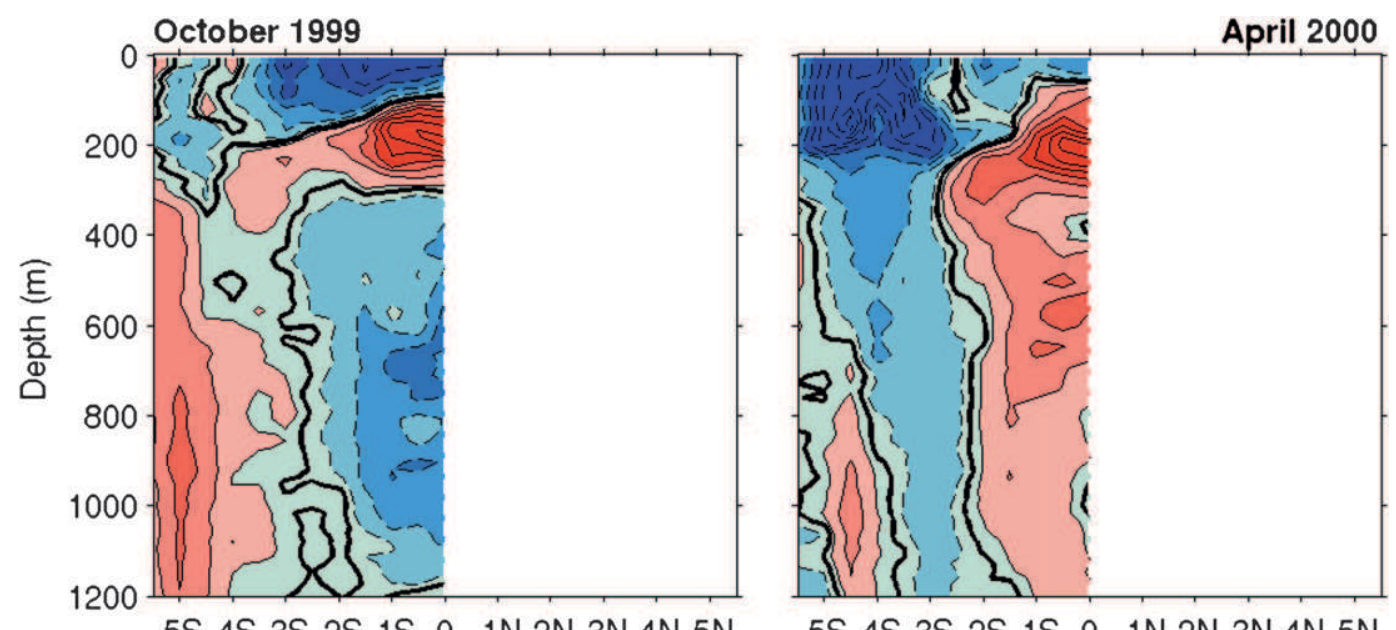

$5 S$ 4S 3S 2S 1S $0 \quad 1 \mathrm{~N} 2 \mathrm{~N} 3 \mathrm{~N} 4 \mathrm{~N} 5 \mathrm{~N}$
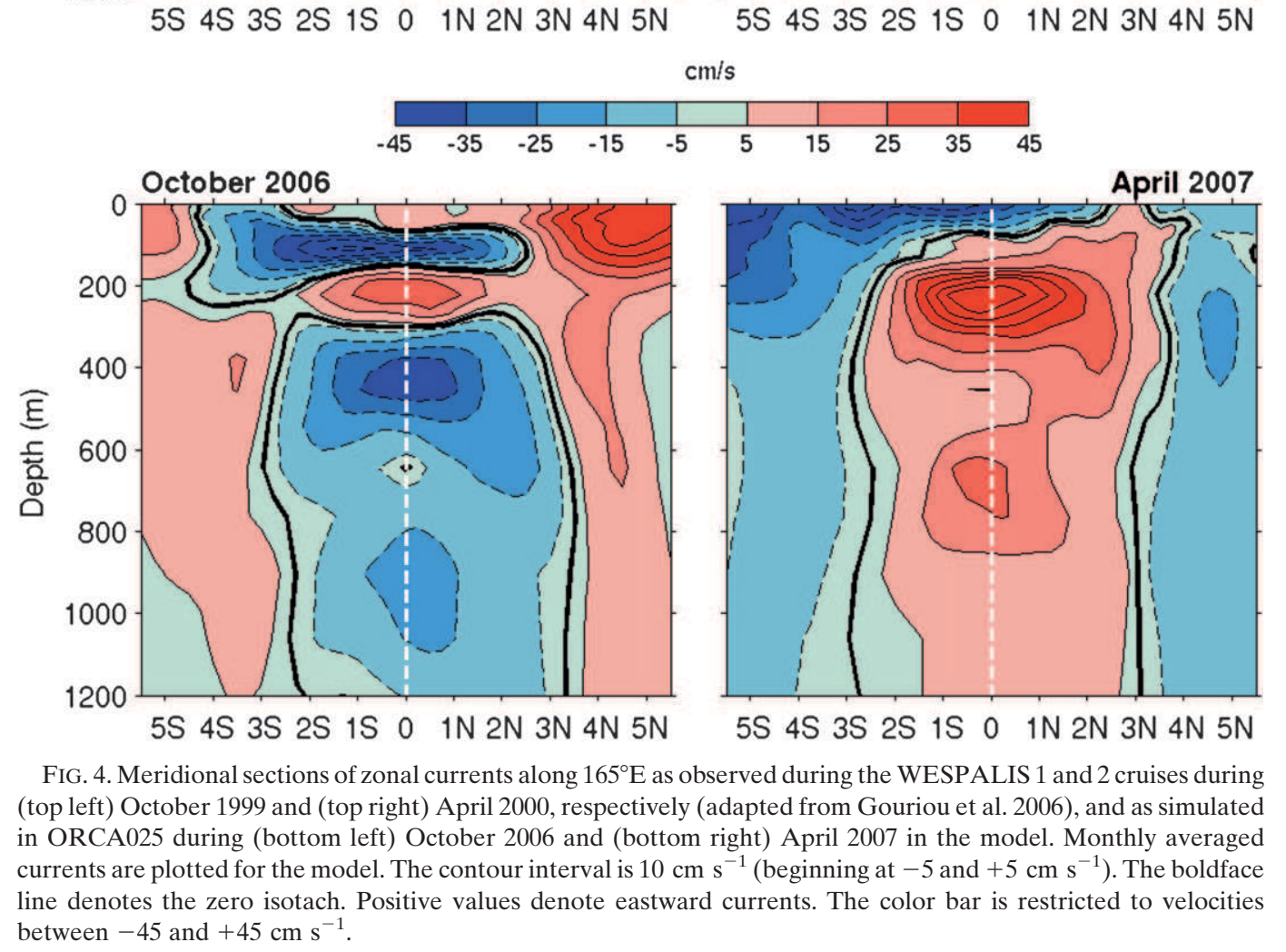

The mean seasonal cycle of zonal velocities associated with the EIC (vertically averaged between 450- and 540-m depths; Fig. 7, left) indicates that velocities were westward from July to February (i.e., 8 months over the course of a year) and eastward from March to June (i.e., 4 months out of the year). The EIC was strongest from September to November, with westward velocities greater than $19 \mathrm{~cm} \mathrm{~s}^{-1}$ at the equator, with the corresponding maximum eastward currents, found in May, of the order of $8 \mathrm{~cm} \mathrm{~s}^{-1}$ at the equator and greater than $12.5 \mathrm{~cm} \mathrm{~s}^{-1}$ at $2.5^{\circ} \mathrm{N}$. Therefore, the EIC in ORCA025 is present in the time average (with mean westward velocities of $\sim 6 \mathrm{~cm} \mathrm{~s}^{-1}$ ) and is subject to an important annual cycle (with a mean peak-to-peak amplitude of $\sim 28 \mathrm{~cm} \mathrm{~s}^{-1}$ ) that is geostrophic, thus strengthening the time-averaged EIC from August to January and weakening (or reversing) the time-averaged EIC from February to July. At greater depths (between 600- and 1300-m depths), the L-EIC was also subject to intense annual variability, for which the timing (westward maximum in August-September and eastward maximum in April) and amplitude (peak-topeak amplitude of $\sim 21 \mathrm{~cm} \mathrm{~s}^{-1}$ ) (Fig. 7 , right) were comparable (though leading by $\sim 1-2$ months) to the one described above for the EIC. 

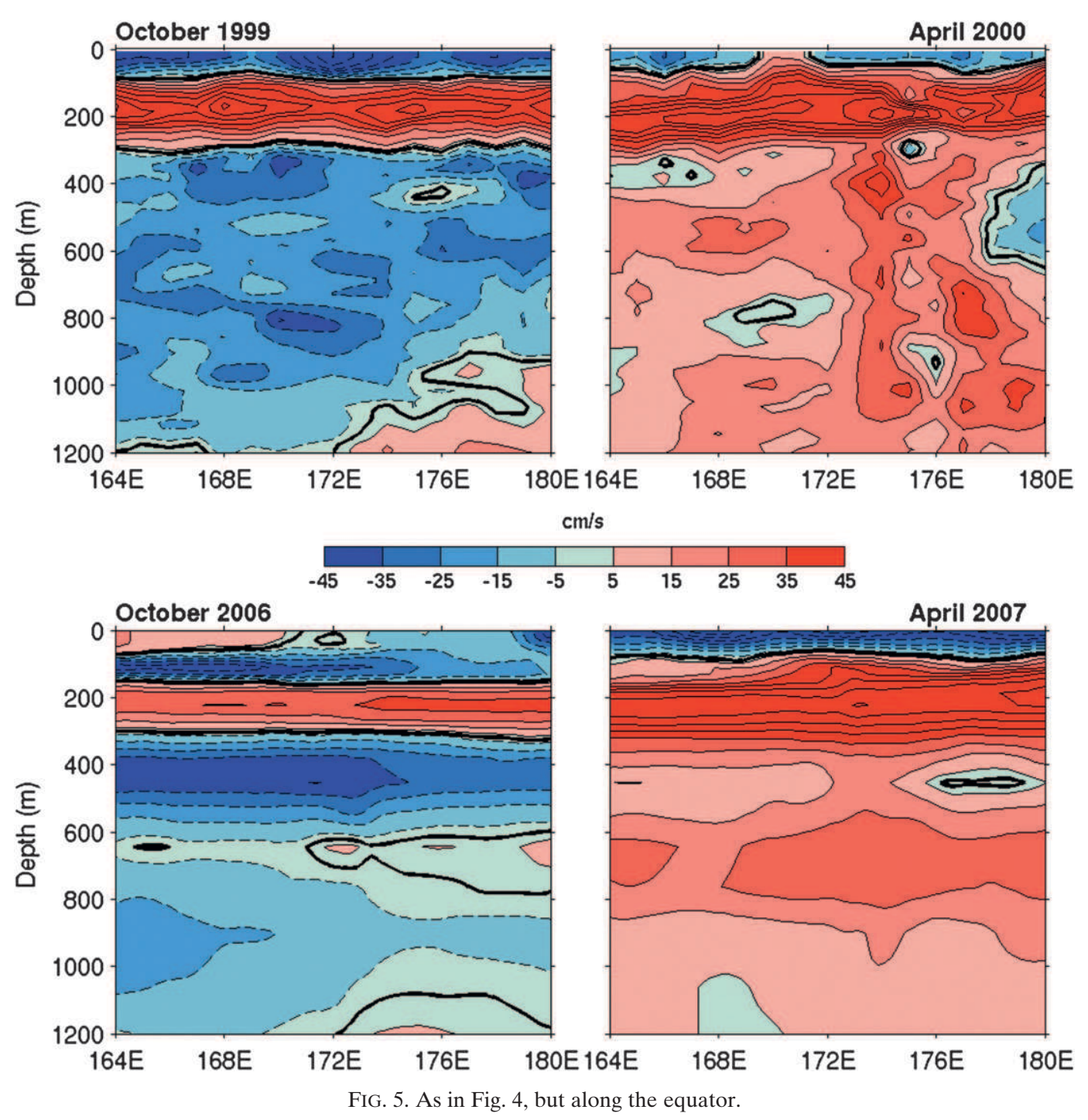

In agreement with observations reported by Firing et al. (1998) and Gouriou et al. (2006), the EIC and L-EIC reversals in April 2007 in ORCA025 were concomitant with the reversal of off-equatorial currents in the same depth range, from eastward (in October) to westward (in April), between $2.5^{\circ}$ and $5^{\circ}$ in latitude in both hemispheres (Fig. 4). The variability in off-equatorial currents was predominantly annual (Figs. 6 and 7), and out of phase (with approximately half the amplitude) with the EIC and the L-EIC annual cycles, suggesting that the EIC and the L-EIC reversals in boreal spring were the near-equatorial manifestation of the reversal of subthermocline horizontal circulations between $5^{\circ} \mathrm{S}$ and $5^{\circ} \mathrm{N}$. Off-equatorial potential temperatures were also found to vary annually in phase on both sides of the equator (Fig. 6, right). However, in contrast with the annual cycle of zonal currents, which was at a maximum at the equator, the strongest amplitudes for the annual cycle in potential temperatures were found off the equator (near $4^{\circ} \mathrm{S}$ and $\left.3^{\circ} \mathrm{N}\right)$.

\section{c. Seasonal cycle of the subthermocline transports}

The EIC and the L-EIC annual reversals are of potential importance for zonal mass exchanges beneath the thermocline in the equatorial Pacific Ocean. Figure 8 and Table 1 compare the zonal transports, calculated between $2^{\circ} \mathrm{S}$ and $2^{\circ} \mathrm{N}$ and between 300- and 600-m depths (depth reached by most S-ADCP observations), from individual S-ADCP meridional sections carried out during 2004-06 at various longitudes, with the corresponding transports calculated from ORCA025 monthly outputs for the same months, years, and longitudes.

In agreement with above velocity comparisons (section 3b), most transports computed using the observations and ORCA025 matched well both in sign and, to a lesser 

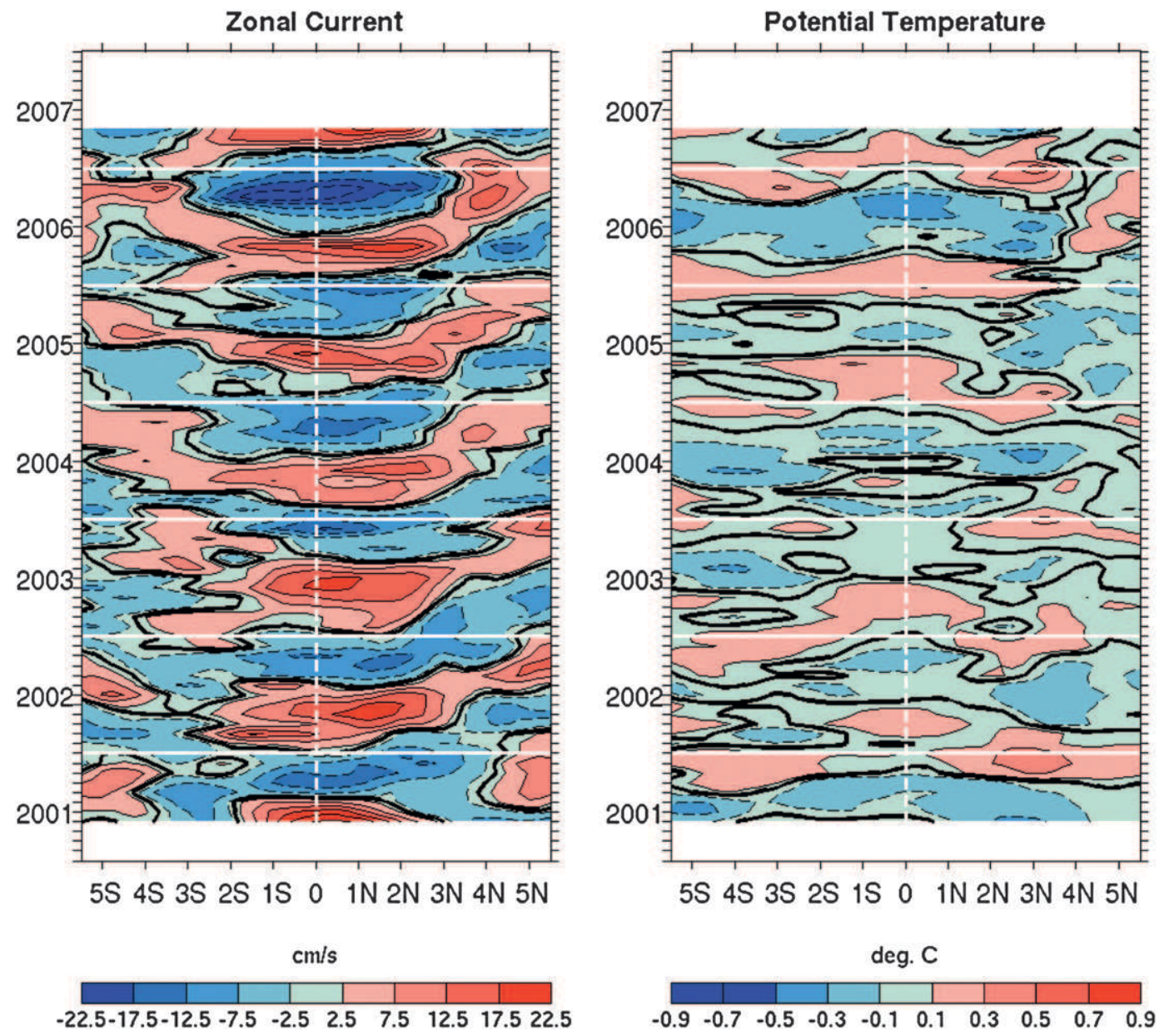

FIG. 6. Latitude-time diagrams of anomalies in (left) simulated zonal velocities and (right) potential temperature from 450 - to $540-\mathrm{m}$ depths, along $165^{\circ} \mathrm{E}$. Both velocities and temperature have their time averages removed, and temperature has been linearly detrended at each latitude. The contour interval is $5 \mathrm{~cm} \mathrm{~s}^{-1}$ for velocities (positive eastward) and $0.2^{\circ} \mathrm{C}$ for temperature. The boldface lines denote the zero isolines.

extent, in amplitude, at all longitudes. In particular, the total ranges of subthermocline zonal transports were similar in S-ADCP observations (from $-24.2 \mathrm{~Sv}$ at $170^{\circ} \mathrm{W}$ in September 2004 to $+21.2 \mathrm{~Sv}$ at $125^{\circ} \mathrm{W}$ in September 2005) and in ORCA025 (from $-22.9 \mathrm{~Sv}$ at $140^{\circ} \mathrm{W}$ in May 2004 to $+15.9 \mathrm{~Sv}$ at $140^{\circ} \mathrm{W}$ in January 2006). Interestingly, despite the limited number of S-ADCP observations, there is some indication in Fig. 8 that zonal transports varied annually at each longitude (with two periods of eastward and westward subthermocline transports over the course of the year), with a phase line of maximum westward transports propagating westward from January -April at $125^{\circ} \mathrm{W}$ to July-December at $165^{\circ} \mathrm{E}$.

A thorough examination of Table 1 shows that zonal transports estimated from observations can vary significantly (more than $10 \mathrm{~Sv}$ ) for the same month interannually (see, e.g., April 2004 versus April 2006 at $110^{\circ} \mathrm{W}$, June 2004 versus June 2005 at $155^{\circ} \mathrm{W}$, July 2004 versus July 2005 at $165^{\circ} \mathrm{E}$ and $170^{\circ} \mathrm{W}$, August 2004 versus August 2005 at $180^{\circ} \mathrm{E}$, or September 2004 versus September 2005 at $125^{\circ} \mathrm{W}$ ). Therefore, the annual cycle alone cannot account for the full temporal variability in observed subthermocline zonal transport. In contrast, transports computed during the same months from ORCA025 monthly outputs showed significantly less interannual variability (except for April 2004 and April 2006 at $110^{\circ} \mathrm{W}$; see Table 1 ). Part of the discrepancy between the observations and the model likely results from the presence of intense high-frequency (intramonthly) variability, as illustrated by the large standard deviations of the ORCA025 intramonthly transports computed using 3-day outputs of the model ( $\sim 6-7 \mathrm{~Sv}$ on average; see Table 1).

Figure 9 presents the time evolution, from May 2001 to April 2007, for the zonal transport across $165^{\circ} \mathrm{E}$ in ORCA025, integrated between 410 and $1340 \mathrm{~m}$ in depth, 


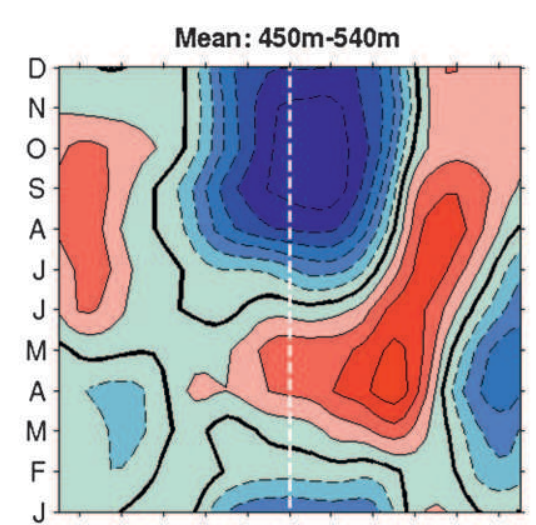

$5 S 4 S$ SS $2 S$ IS $0 \quad 1 \mathrm{~N} 2 \mathrm{~N} 3 \mathrm{~N} 4 \mathrm{~N} 5 \mathrm{~N}$

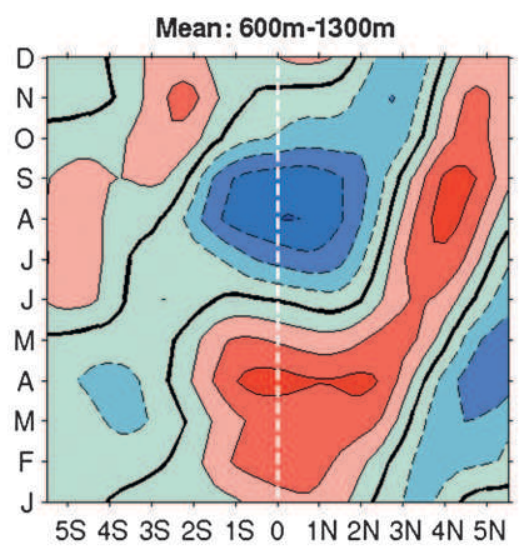

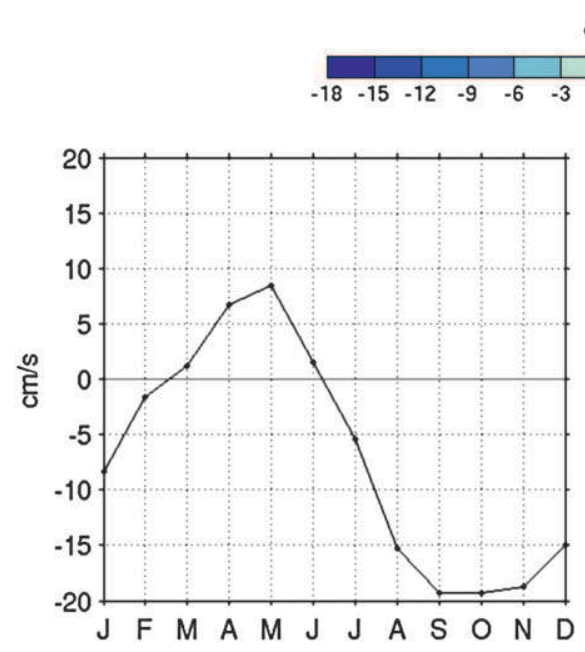

$\mathrm{cm} / \mathrm{s}$

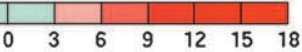

FIG. 7. The mean seasonal cycle of zonal velocities at $165^{\circ} \mathrm{E}$ from the ORCA025 simulation with respect to (top) latitude and (bottom) at the equator in two different layers: (left) 450-540and (right) 600-1300-m depths. The mean seasonal cycle was computed over the period from May 2001 to April 2007. The contour interval in the top panel is $3 \mathrm{~cm} \mathrm{~s}^{-1}$. Positive values denote eastward currents.

from $2^{\circ} \mathrm{S}$ to $2^{\circ} \mathrm{N}$ (including both the EIC and the L-EIC, red curve) and in the two latitudinal bands between $2^{\circ}$ and $5.5^{\circ}$ on both sides of the equator. As expected from the above description of the zonal velocities, the time variability in the monthly zonal transport was predominantly annual at and off the equator. At the equator, maximum westward transports associated with the EIC and the L-EIC in August-September (from -36 to $-70 \mathrm{~Sv}$ depending on the year) were found to reverse each year to maximum eastward transports in April $(\geq+40 \mathrm{~Sv}$ each year, except in 2004). The mean peakto-peak amplitude in the annual cycle of the zonal transport at the location of the EIC and the L-EIC therefore amounted to $\sim 70 \mathrm{~Sv}$ [i.e., approximately 4 times the mean transport $(\sim 18 \mathrm{~Sv})$ of the EUC at this longitude (Picaut and Tournier 1991; Gouriou and Toole 1993; Johnson et al. 2002)]. Note that an interannual modulation in the amplitude of this annual cycle is seen in
Fig. 9, with the largest peak-to-peak variations occurring in 2006-07 (>120 Sv) and the weakest ones occurring in 2003-04 ( $\sim 50 \mathrm{~Sv})$.

The corresponding zonal transports off the equator (between $2^{\circ}$ and $5.5^{\circ}$ in latitude; Fig. 9) are out of phase with the equatorial ones, with maximum off-equatorial eastward transports occurring simultaneously with maximum equatorial westward transports and vice versa. Zonal transports north and south of the equator have comparable magnitudes throughout the period of the study, and partly balance, when added, the annual cycle of the zonal transport associated with the EIC and the L-EIC. The finding shows that, on seasonal time scales, the EIC and L-EIC are the equatorial branches of two horizontal circulation patterns on both sides of the equator that include the above off-equatorial currents and that reverse simultaneously over the course of the year. However, it must be noted that off-equatorial transports 


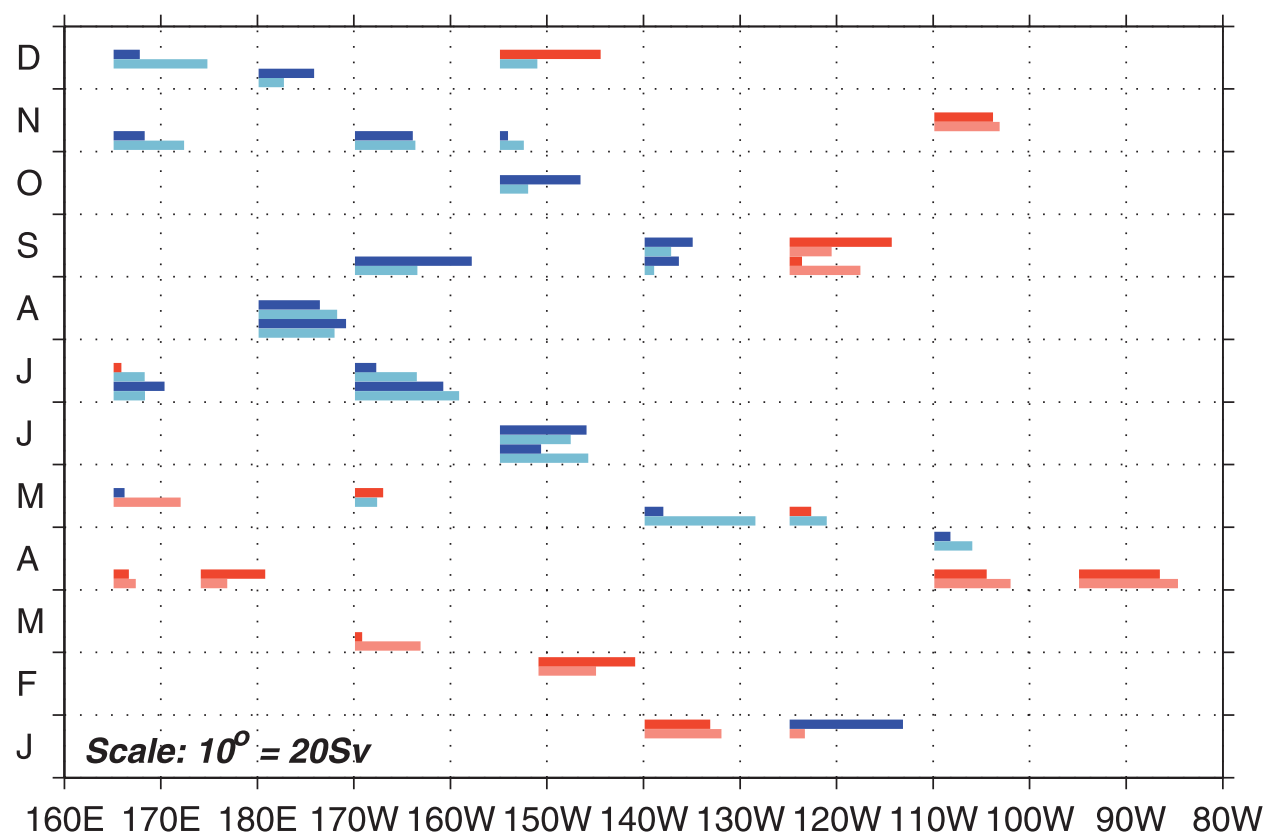

FIG. 8. The longitude-time evolution of the EIC transports (Sv) by month from various cruises carried out in the tropical Pacific Ocean between 2004 and 2006 (see Table 1) and the corresponding month and year in the ORCA025 simulation. Transports were computed between $2^{\circ} \mathrm{S}$ and $2^{\circ} \mathrm{N}$ and between 300 - and 600-m depths. Red (blue) denote eastward (westward) transports, and upper dark (lower bright) bars denote transports from S-ADCP observations (from the model). Several estimates are available for a particular month and longitude [e.g., at $110^{\circ} \mathrm{W}$, in April, where the top and bottom groups of bars correspond to the KA0401 (2004) and KA0602 (2006) cruises, respectively (see Table 1)].

experience less interannual variability in ORCA025 than their equatorial counterparts. Unlike the annual cycle, the interannual variability of the EIC and the L-EIC does not seem to be directly associated with these subthermocline horizontal circulations.

Despite the limited vertical resolution $(\sim 100-200 \mathrm{~m})$ at intermediate depths in ORCA025, good agreement was found between EIC-L-EIC properties using the available observations and the model, giving us confidence that the annual cycle in the subthermocline was realistic in ORCA025 and most likely the cause for large changes in the EIC-L-EIC zonal transports that were observed by Gouriou et al. (2006). In the next section, we discuss the mechanisms responsible for this subthermocline annual cycle in the model.

\section{Mechanisms for the EIC seasonal variability}

\section{a. Evidence of a vertically propagating annual Rossby wave}

To investigate the mechanisms responsible for the annual cycle of both the EIC and L-EIC, Fig. 10 presents the longitude-depth distributions of the amplitude, phase, and percentage of explained variance for the annual harmonic in zonal velocities along the equator in ORCA025. Two distinct regions can be identified as follows:
1) above and west of a line schematically extending from $110^{\circ} \mathrm{W}$, at $200-\mathrm{m}$ depth, to approximately $170^{\circ} \mathrm{E}$, and 2000-m depth, the annual harmonic explains $60 \%-$ $90 \%$ of the variance of the total zonal currents, with an amplitude greater than $8 \mathrm{~cm} \mathrm{~s}^{-1}$, and

2) below and east of this line, a "shadow zone" is present where the amplitude and percentage of the explained variance of the annual harmonic tend to vanish (except near $120^{\circ} \mathrm{W}$ where a weak local maximum was found below $800 \mathrm{~m}$ ).

The region where subthermocline zonal currents experience annual variability thus progressively thickens toward the west, extending to greater depths in the western half of the equatorial Pacific.

At $165^{\circ} \mathrm{E}$, the annual harmonic of the zonal velocities at the equator (Fig. 10) explains more than $70 \%$ of the total variance from 200 to $2000 \mathrm{~m}$, and captures the main characteristics of the seasonal cycle of subthermocline currents that were described previously. In agreement with Fig. 7, the amplitude of the annual harmonic is $\sim 15-20 \mathrm{~cm} \mathrm{~s}^{-1}$ at $500-\mathrm{m}$ depth and $\sim 10-12 \mathrm{~cm} \mathrm{~s}^{-1}$ near 1000-m depth, with maximum eastward currents in April and February, respectively, at these two depths (consistent with the 1-2-month phase lag between the EIC and the L-EIC). 


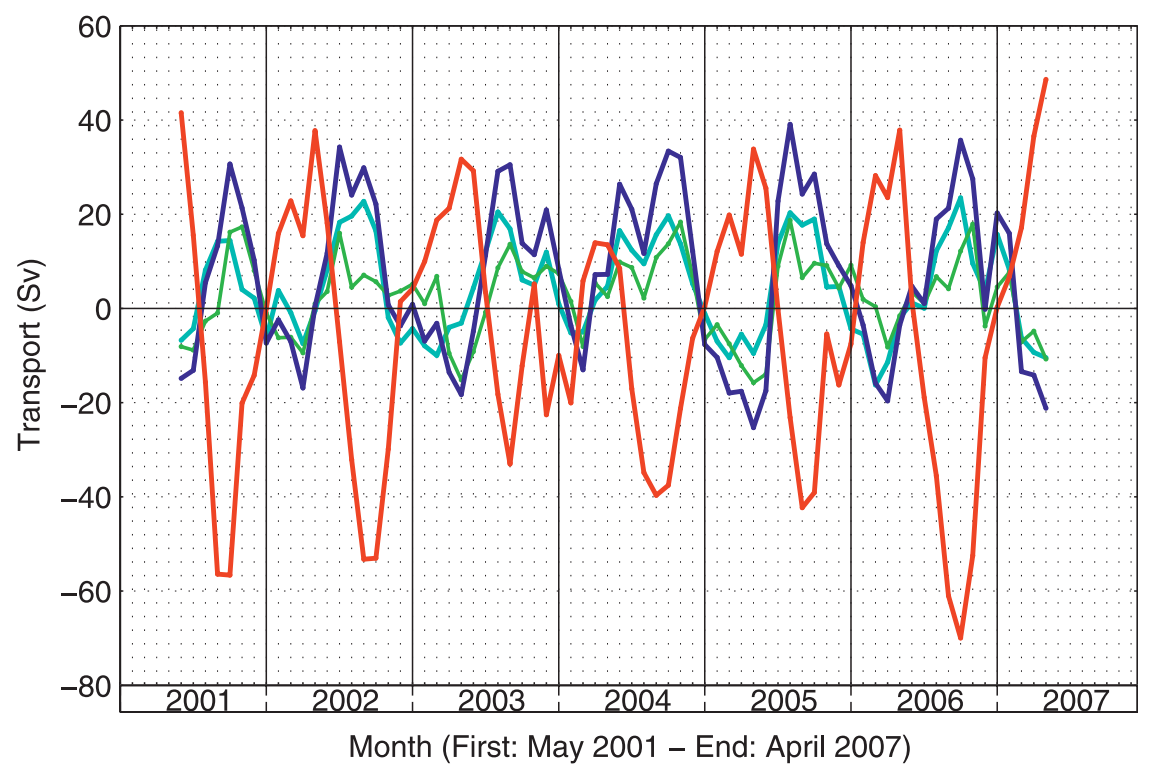

FIG. 9. The time evolution of zonal transports (Sv) across $165^{\circ} \mathrm{E}$ between 410 - and $1340-\mathrm{m}$ depths in ORCA025 in four ranges of latitudes: the equatorial contribution (red, $\left.2^{\circ} \mathrm{S}-2^{\circ} \mathrm{N}\right)$, the northern extraequatorial contribution (cyan, $2^{\circ}-5.5^{\circ} \mathrm{N}$ ), the southern extraequatorial contribution (green, $5.5^{\circ}-2^{\circ} \mathrm{S}$ ), and the total extraequatorial contribution (blue, $5.5^{\circ}-2^{\circ} \mathrm{S}+2^{\circ}-5.5^{\circ} \mathrm{N}$ ). Positive transports are eastward flows.

Following Lukas and Firing (1985) or Kessler and McCreary (1993), we estimated the vertical isothermal displacements at each depth and longitude using $\zeta=$ $T_{A} /(\partial \bar{T} / \partial z)$, where $T_{A}$ is the amplitude of the annual harmonic and $(\partial \bar{T} / \partial z)$ is the mean vertical gradient of the potential temperature. Vertical isothermal displacements are at a maximum below the thermocline near $3^{\circ} \mathrm{N}$ and $3^{\circ} \mathrm{S}$, that is, at the latitudes where seasonal anomalies in subsurface temperature were found to be at a maximum (Fig. 6, right). The amplitudes and explained variances in the annual harmonic of the vertical isotherm displacements along $3^{\circ} \mathrm{N}$ (Fig. 11) have similar spatial patterns to the annual harmonic of the zonal velocities along the equator (Fig. 10). A comparable distribution was obtained along $4^{\circ} \mathrm{N}$ from hydrographic observations in the tropical Pacific by Kessler and McCreary (1993, their Fig. 2), confirming that ORCA025 realistically simulates the annual cycle beneath the thermocline. Such a distribution was also found and discussed in an OGCM by Dewitte and Reverdin (2000). Note, however, that the maximum amplitudes $(>30 \mathrm{~m})$ of the annual harmonic appear in two separate depth ranges, first between 300 and $600 \mathrm{~m}$ (at the depth of the EIC) and second below $800 \mathrm{~m}$ (at the depth of, and below, the L-EIC), with a relative minimum (lower than $20 \mathrm{~m}$ ) between them. Such a detailed vertical structure is also present, though less marked, for zonal velocities at the equator (Fig. 10), which was not apparent in Kessler and McCreary (1993).
The phase of the strongest eastward currents (Fig. 10) increases westward and upward. Phase isolines are all approximately parallel, from the bottom of the thermocline (in the eastern half of the Pacific) to a depth of $2000 \mathrm{~m}$ (in the western half of the basin), and closely follow the Wentzel-Kramers-Brillouin (WKB) ray path of the vertically propagating meridional mode 1 Rossby wave, as previously noted by Kessler and McCreary (1993). Similar westward and upward phase propagation was also seen, though less distinctly, in isotherm displacements (Fig. 11). A comparison of phases along the WKB ray path (thick white lines) in Fig. 10 (December) and Fig. 11 (September) suggests that the annual cycle of isothermal displacements leads the annual cycle of zonal velocities by a quarter cycle (i.e., 3 months) in the deep ocean. In addition, the zonal and vertical wavelengths of this annual wave can be estimated, respectively, using a linear fit to phases in the zonal and vertical directions (between $160^{\circ} \mathrm{E}$ and $155^{\circ} \mathrm{W}$ and between 450 - and $1300-\mathrm{m}$ depths). Our estimates (respectively, $16300 \pm 3000 \mathrm{~km}$ for the zonal wavelength and $3900 \pm 800 \mathrm{~m}$ for the vertical wavelength) are in good agreement with estimates based on observations (Lukas and Firing 1985; Kessler and McCreary 1993). These estimates, along with the quadrature found between the annual cycles of isotherm displacements and zonal velocities, support both the downward propagation of an annual Rossby wave emanating from the base of the thermocline in the eastern Pacific, in ORCA025, as in the observations. Therefore, 

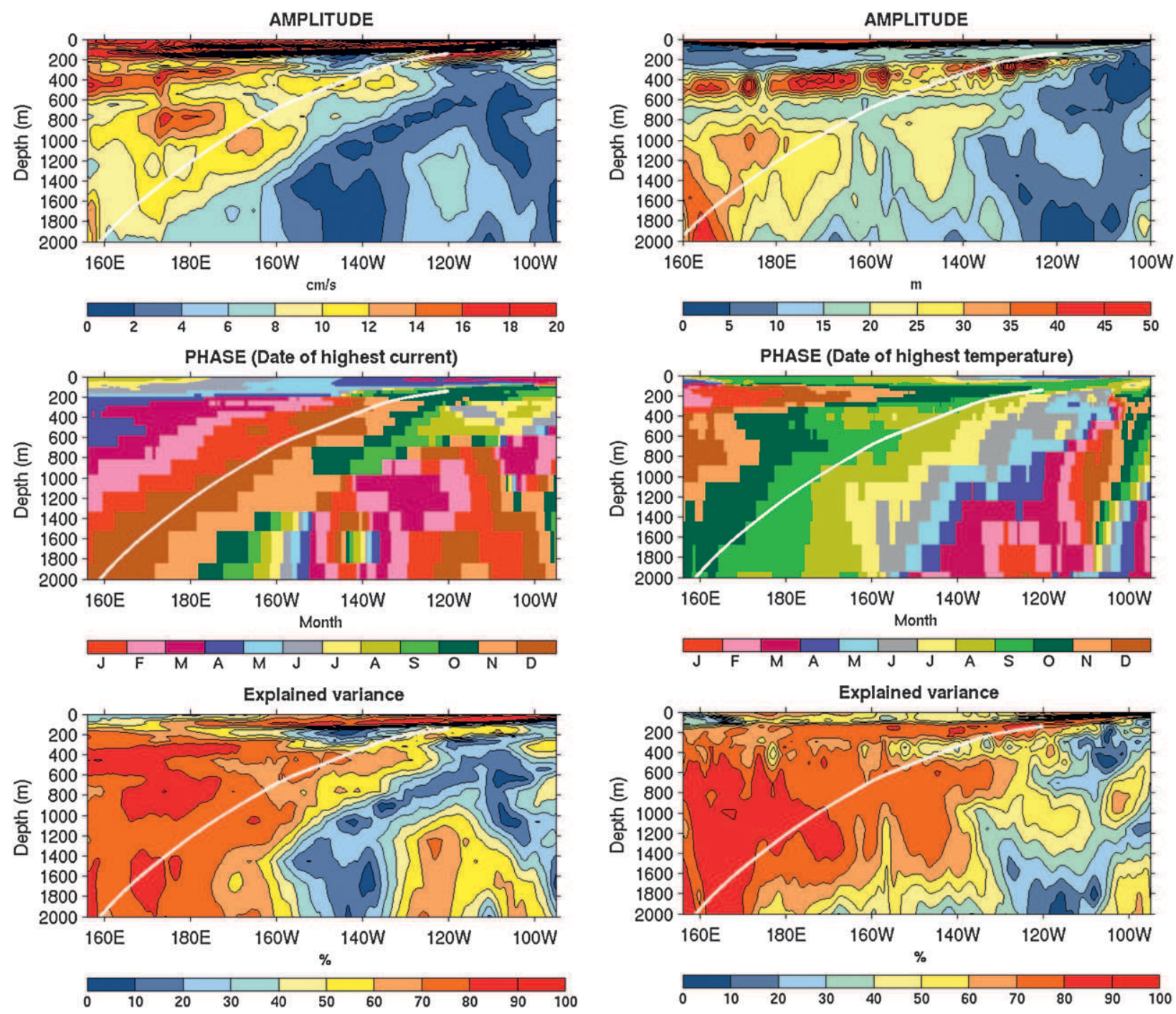

FIG. 10. The annual harmonic of monthly averaged zonal velocities along the equator from the ORCA025 simulation: (top) the amplitude $\left(\mathrm{cm} \mathrm{s}^{-1}\right)$, (middle) the phase (month), and (bottom) the explained variance $(\%)$. The phase is defined by the month of the strongest eastward currents. The WKB ray path of a vertically propagating meridional mode 1 Rossby wave originating from the eastern Pacific is superimposed.

annual Rossby waves appear to be good candidates for driving the annual cycle of subthermocline currents in the western half of the basin.

East of $110^{\circ} \mathrm{W}$, additional downward-slanting phase lines are present below the thermocline (Fig. 11). A similar feature was found in Kessler and McCreary (1993) and associated with the vertical propagation of a meridional mode 3 Rossby wave generated by reflection at the eastern boundary. However, in the model, the amplitude is rapidly attenuated away from the boundary. Note that such a feature is not clearly present in the annual harmonic of the zonal velocities along the equator (Fig. 10).

FIG. 11. As in Fig. 10, but for estimated vertical displacement (m) of monthly averaged isotherms along $3^{\circ} \mathrm{N}$.

\section{b. CEOF decomposition}

The presence of a vertically propagating annual Rossby wave in the equatorial Pacific was further seen with a complex empirical orthogonal functions (C-EOFs; Barnett 1983) decomposition of the monthly averaged zonal velocities along the equator in ORCA025. Unlike EOF decompositions, the C-EOF method is able to isolate dominant patterns of variability that propagate in time and space. The principal component (time evolution) and spatial patterns (real and imaginary parts) of the first C-EOF mode, accounting for $51 \%$ of the total variance, are presented in Fig. 12. The mode was computed between 200- and 2000-m depths in order to get rid of the strongly energetic near-surface currents, the SEC and the EUC. The temporal evolution of this mode 
(Fig. 12, top) is similar to the time evolution of the zonal transport below the thermocline and between $2^{\circ} \mathrm{S}$ and $2^{\circ} \mathrm{N}$ at $165^{\circ} \mathrm{E}$ (Fig. 9), capturing both the predominance of an annual cycle and some interannual variability (the strongest event in 2006-07 and the weakest event in 2003-04).

The zonal velocity field resulting from this C-EOF mode was $\lambda_{r}(t) C_{r}(x, z)+\lambda_{i}(t) C_{i}(x, z)$, where $\lambda_{r}(t)$ and $\lambda_{i}(t)$ are the real and imaginary principal components (PC), and $C_{r}(x, z)$ and $C_{i}(x, z)$ are the real and imaginary spatial patterns. In April of each year, the imaginary PC (blue line) vanished and the real PC (red line) was positive: the real spatial pattern of the first C-EOF mode (Fig. 12, middle) then accounted for the distribution of the zonal velocities along the equator, and corresponded to months when both the EIC and the L-EIC at $165^{\circ} \mathrm{E}$ flowed eastward (Fig. 7), in agreement with strong positive anomalies $\left(>7.5 \mathrm{~cm} \mathrm{~s}^{-1}\right)$ extending downward from 200 to $2000 \mathrm{~m}$ at that longitude. The same spatial pattern, with opposite signs, occurred in October, when the imaginary PC again vanished each year but when the real $\mathrm{PC}$ was negative, corresponding to the month when the EIC and the L-EIC were at their yearly maxima at $165^{\circ} \mathrm{E}$.

In the opposite situation, when the real PC vanished (during July and January in most years), the imaginary spatial pattern (Fig. 12, bottom) accounted for the equatorial distribution of the zonal velocities (as occurs in July when the imaginary $\mathrm{PC}$ is positive, with the opposite sign in January when the imaginary PC is negative). During these months, zonal velocity anomalies are of opposite signs above and beneath $800 \mathrm{~m}$ at $165^{\circ} \mathrm{E}$. The spatial and imaginary patterns illustrate the upward and westward propagation of the negative anomalies, which are seen at middepths and in the center of the basin in April (Fig. 12, middle), subsequently fully occupy the region west of $160^{\circ} \mathrm{W}$ in July (Fig. 12, lower), and finally cover only a small fraction of the upper western corner of the basin in October (Fig. 12, middle; with the opposite sign). The comparison of Figs. 8 and 12 shows that this C-EOF mode explains well the seasonal variability of near-equatorial transports (between 300- and 600-m depths) along the equator, in particular the westward propagation and the timing of the maximum westward transports at each longitude (in November-December at $165^{\circ} \mathrm{E}$, in JulySeptember near $\left.170^{\circ} \mathrm{W}\right)$.

A similar C-EOF decomposition was performed on the meridional section of the ORCA025 zonal velocities along $165^{\circ} \mathrm{E}$ (Fig. 13). The first mode explained $68 \%$ of the total variance. As before, the real part (Fig. 13, middle) captures the large-scale vertical structures of positive velocity anomalies at the equator extending downward from 200 to $2000 \mathrm{~m}$ in March-April and reversing to negative velocity anomalies in September-

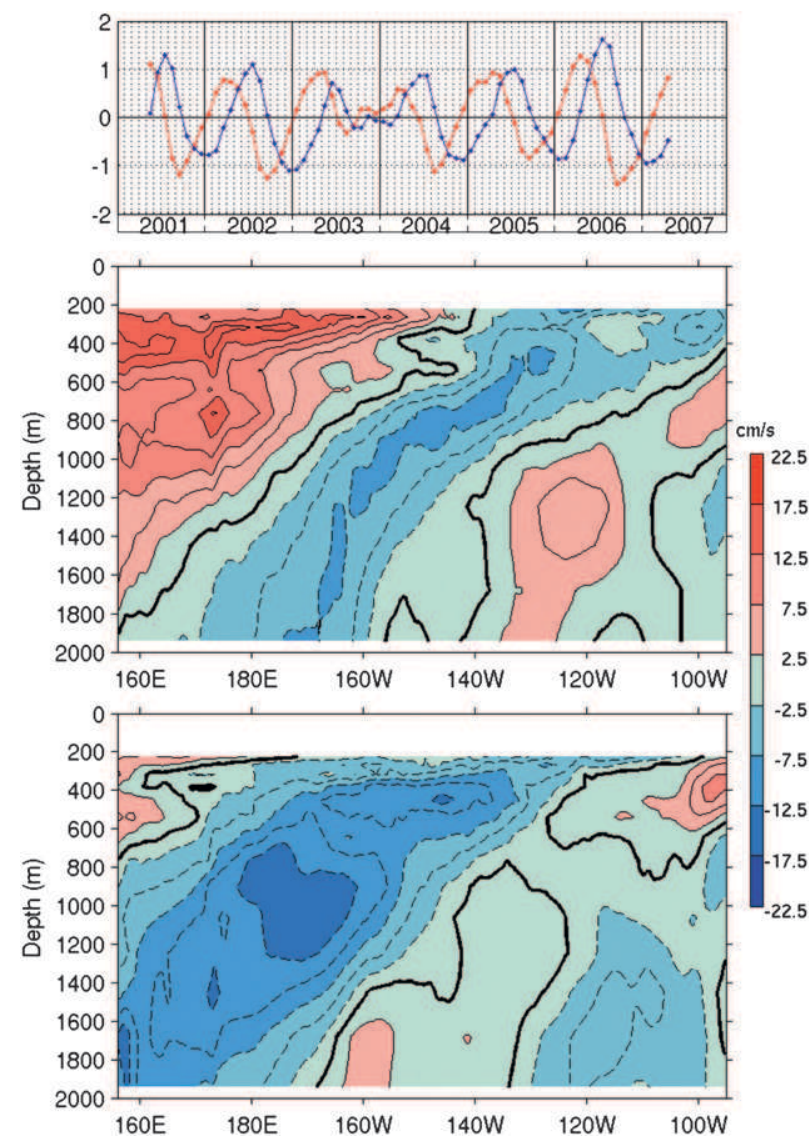

FIG. 12. The first mode of the C-EOF decomposition of monthly averaged zonal velocities along the equator in the ORCA025 simulation: (top) time evolution (in red and blue) and the spatial distribution of the (middle) real and (bottom) imaginary parts. The contour interval is $5 \mathrm{~cm} \mathrm{~s}^{-1}$. The boldface line denotes the zero isotach. The C-EOF decomposition was computed between 200and 2000-m depths. A positive product between the time function and spatial distribution denotes anomalous eastward currents.

October. The anomaly is associated with westward offequatorial currents on both sides of the equator that have maxima centered near $4^{\circ} \mathrm{N}$ and $5^{\circ} \mathrm{S}$. The meridional structure is also in large part compatible with a vertically propagating meridional mode 1 Rossby wave, even though a weak asymmetry in the amplitude and latitude of the maximum off-equatorial currents can be seen. The imaginary part (Fig. 13, bottom) agrees with Fig. 12 (bottom) and illustrates the phase lag in the vertical direction between the annual cycles of the EIC and L-EIC between $2^{\circ} \mathrm{S}$ and $2^{\circ} \mathrm{N}$.

\section{c. Forcing of the annual variability}

Using a linear continuously stratified model, Kessler and McCreary (1993) demonstrated that the annual Rossby wave that they observed in the subthermocline was generated by the westward-propagating component 

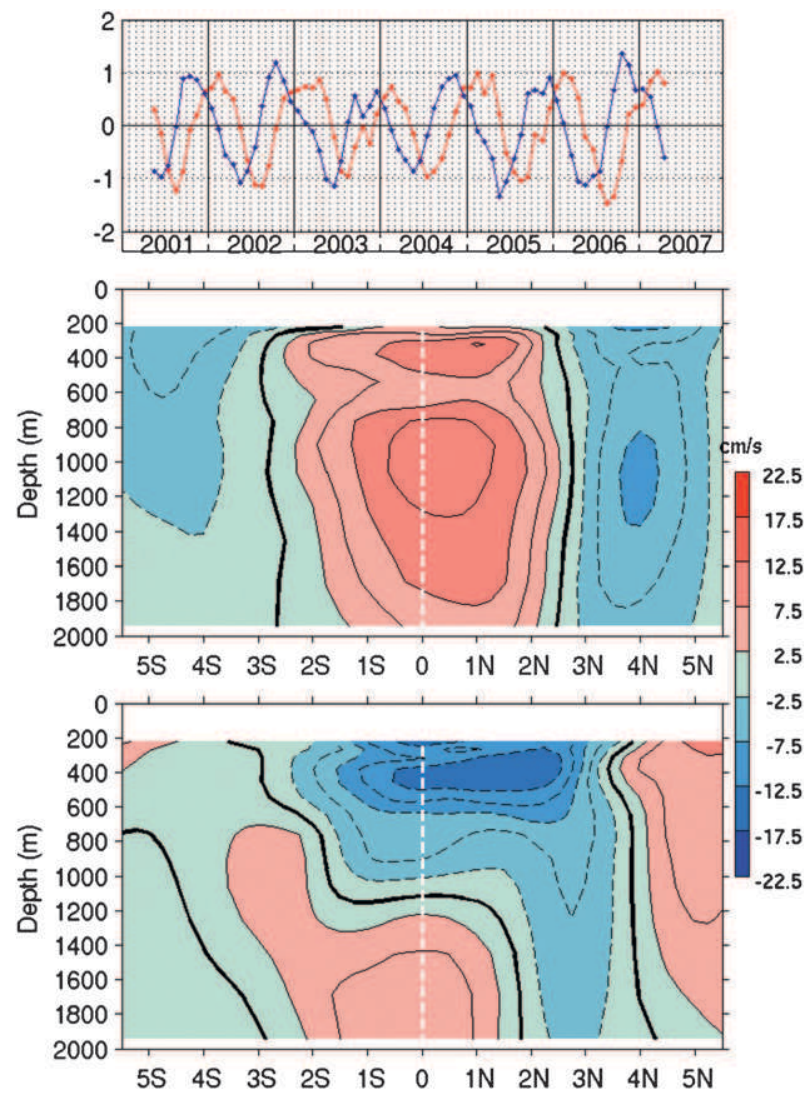

FIG. 13. As in Fig. 12, but along $165^{\circ} \mathrm{E}$.

of the zonal wind in the equatorial Pacific. Using this viewpoint, the main characteristics of the vertically propagating Rossby wave (amplitude, period, and zonal wavelength) were therefore externally constrained by the corresponding characteristics of the westward-propagating zonal wind stress along the equator.

To investigate the role of annual wind forcing on the generation of the annual Rossby wave in our simulation, Fig. 14 presents the amplitude, the phase, and the explained variance of the annual harmonic of the zonal component of the ECMWF wind stress (used to force the model). As previously described by Lukas and Firing (1985), Kessler and McCreary (1993), and Dewitte and Reverdin (2000), the annual component of zonal wind stress above the equatorial Pacific essentially consists of two distinct signals:

1) away from the equator, a standing annual variability predominates, explaining more than $60 \%$ of the total variance, and is at a maximum in August and January, respectively, in the Northern and Southern hemispheres, and

2) in close vicinity to the equator, the annual zonal wind stress propagates westward with maximum magnitudes between $3^{\circ} \mathrm{S}$ and $1^{\circ} \mathrm{N}$ east of $140^{\circ} \mathrm{W}$, explaining more than $60 \%$ of the total variance. Note the presence of a second, weaker, relative maximum at the equator near $165^{\circ} \mathrm{E}$ that explains approximately $40 \%$ of the total variance near this longitude. Along the equator, the phase of the annual wind (Fig. 14, middle) propagates nearly linearly from east to west: the apparent zonal wavelength ( $\sim 15300 \mathrm{~km}$, as estimated from a linear fit to phases) is similar to the one obtained before for the annual Rossby wave in the ocean (see section 4a), in agreement with Kessler and McCreary (1993).

The longitude-time diagram of zonal wind stress anomalies along the equator (Fig. 15, left) reveals a significant interannual variability in the amplitude of the seasonal cycle, both east of $170^{\circ} \mathrm{W}$ (with stronger than usual eastward anomalies in the first half of 2001 and 2007 ) and west of $170^{\circ} \mathrm{W}$ (with stronger than usual eastward anomalies in boreal fall/winter 2001, 2002, and 2006). The zonally averaged interannual modulation in the annual cycle of the equatorial wind stress over the whole equatorial Pacific can be inferred from Fig. 15 (right). To take into account the westward-propagating nature of the annual zonal wind stress along the equator, the zonal average was performed along the mean phase lines deduced from Fig. 14 (thick purple lines in Fig. 15, left). The mean amplitude of the seasonal cycle was found to be at least 2 times stronger in 2001, 2002, and in 2006 than in 2003 or 2004. Interestingly, the comparison of Fig. 15 (right) to Fig. 9 shows that the interannually varying amplitudes of the seasonal cycles of zonal wind stress anomalies along the equator, and of the subthermocline zonal transports associated with the EIC and the L-EIC across $165^{\circ} \mathrm{E}$, are in good agreement. The finding suggests that the interannual modulation in the amplitude of the annual Rossby wave in the subthermocline, and of the resulting reversal of the EIC and the L-EIC at $165^{\circ} \mathrm{E}$, is externally forced by the interannual variability of the westward-propagating annual zonal wind stress along the equator.

\section{Discussion and conclusions}

The numerous ADCP observations analyzed here (Table 1) indicate that the large reversal of near-equatorial subthermocline zonal transports observed between October 1999 and April 2000 in the western Pacific (Gouriou et al. 2006) was not an isolated event. Instead, an intense time variability of subthermocline zonal currents was observed over many years and throughout the Pacific Ocean along the equator. These observations are still too sparse to fully document the main properties 

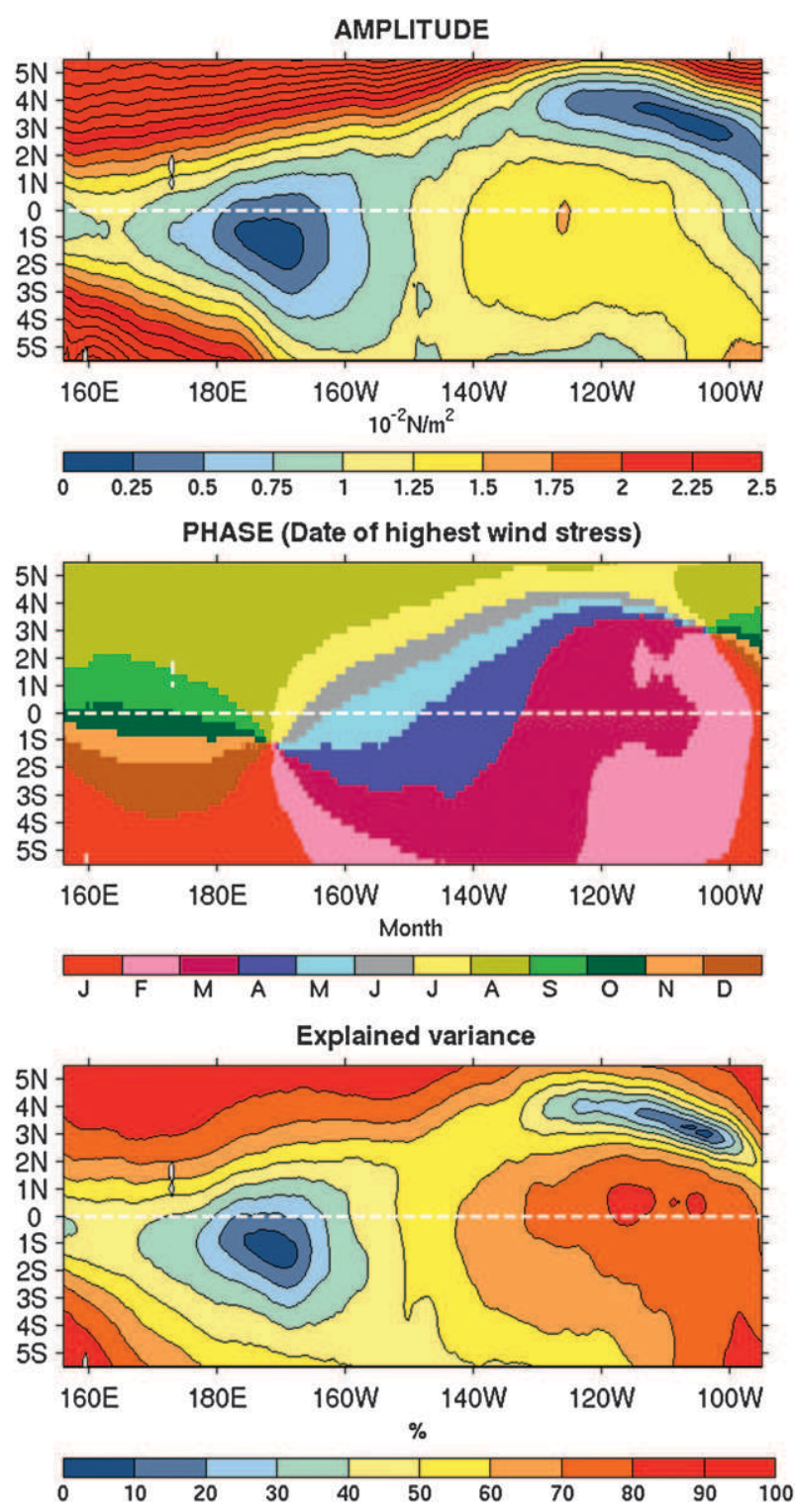

FIG. 14. The spatial distribution of the annual harmonic of the monthly averaged zonal wind stress in the ORCA025 simulation: (top) the amplitude $\left(10^{-2} \mathrm{~N} \mathrm{~m}^{-2}\right)$, (middle) the phase (month), and (bottom) the explained variance (\%). The phase is defined as the month of the strongest eastward wind stress anomalies.

of this variability. An OGCM simulation for the tropical Pacific Ocean, which is capable of simulating such a 6-month reversal with realistic amplitude, was analyzed to determine the origins of the variability. The simulation indicates that this reversal is the signature of an intense annual variability of middepth equatorial currents. The main mechanism responsible for this variability was the presence of annual meridional mode 1 Rossby waves below the thermocline. The Rossby waves are generated in the upper ocean by the westward-propagating annual component of the equatorial zonal wind stress and, subsequently, propagate downward to great depths in the western Pacific Ocean. The existence of such annual vertically propagating Rossby waves was previously inferred in the literature from subsurface temperature observations alone (Lukas and Firing 1985; Kessler and McCreary 1993). The present work is, to our knowledge, the first to address questions relating to the impacts of these annual Rossby waves on middepth zonal mass transports in the equatorial Pacific, in relation to ADCP observations.

Comparable annual variability for zonal currents has been observed below the thermocline in the equatorial Atlantic from S-ADCP and L-ADCP observations (Brandt and Eden 2005). In the Atlantic, as well as in the Pacific, the mechanisms by which annual wind forcing at the surface can penetrate across the sharp equatorial thermocline are still being debated. Using an analytical study, Gent and Luyten (1985) suggested that the thermocline should reflect most of the wind-induced vertical energy flux, meaning that most of the annual variability would remain confined to the upper ocean. On the other hand, Rothstein et al. (1985) found that the energy associated with the periodic forcing of equatorial Kelvin waves could propagate throughout the pycnocline, due to multiple partial reflections of energy waves in the thermocline and at the ocean surface. Recently, Dewitte and Reverdin (2000), for the Pacific, and Thierry et al. (2004) and Brandt and Eden (2005), for the Atlantic, showed that the annual variability in middepth ocean in numerical simulations was related to the presence of not only wind-generated Kelvin and Rossby beams, but also to Rossby beams generated by the reflection of windgenerated Kelvin beams at the eastern boundary. Such reflected Rossby waves were also found in the analytical model by Kessler and McCreary (1993); however, the influences of these reflections in the deep ocean have never been convincingly demonstrated from observations until now. The debate is thus still open.

The large amplitudes of the annual cycles of the subthermocline currents $\left(15 \mathrm{~cm} \mathrm{~s}^{-1}\right.$ for the EIC and $10 \mathrm{~cm} \mathrm{~s}^{-1}$ for the L-EIC; see Fig. 7), significantly exceeding the long-term means of these currents $\left(10 \mathrm{~cm} \mathrm{~s}^{-1}\right.$ for the EIC and $5 \mathrm{~cm} \mathrm{~s}^{-1}$ for the L-EIC; see Fig. 3) along with the great depths reached by annual Rossby waves in the western Pacific, lead to huge variations in the subthermocline zonal transports between $2^{\circ} \mathrm{S}$ and $2^{\circ} \mathrm{N}$ in the western Pacific at seasonal time scales (from $\sim 50 \mathrm{~Sv}$ westward in October to $\sim 50 \mathrm{~Sv}$ eastward in April, between $300-$ and $1200-\mathrm{m}$ depths, across $165^{\circ} \mathrm{E}$ ). This large transport variability below the thermocline raises questions regarding its importance for the zonal mass and heat balance of the equatorial Pacific Ocean. To quantify the respective roles for the mean and temporally varying, 

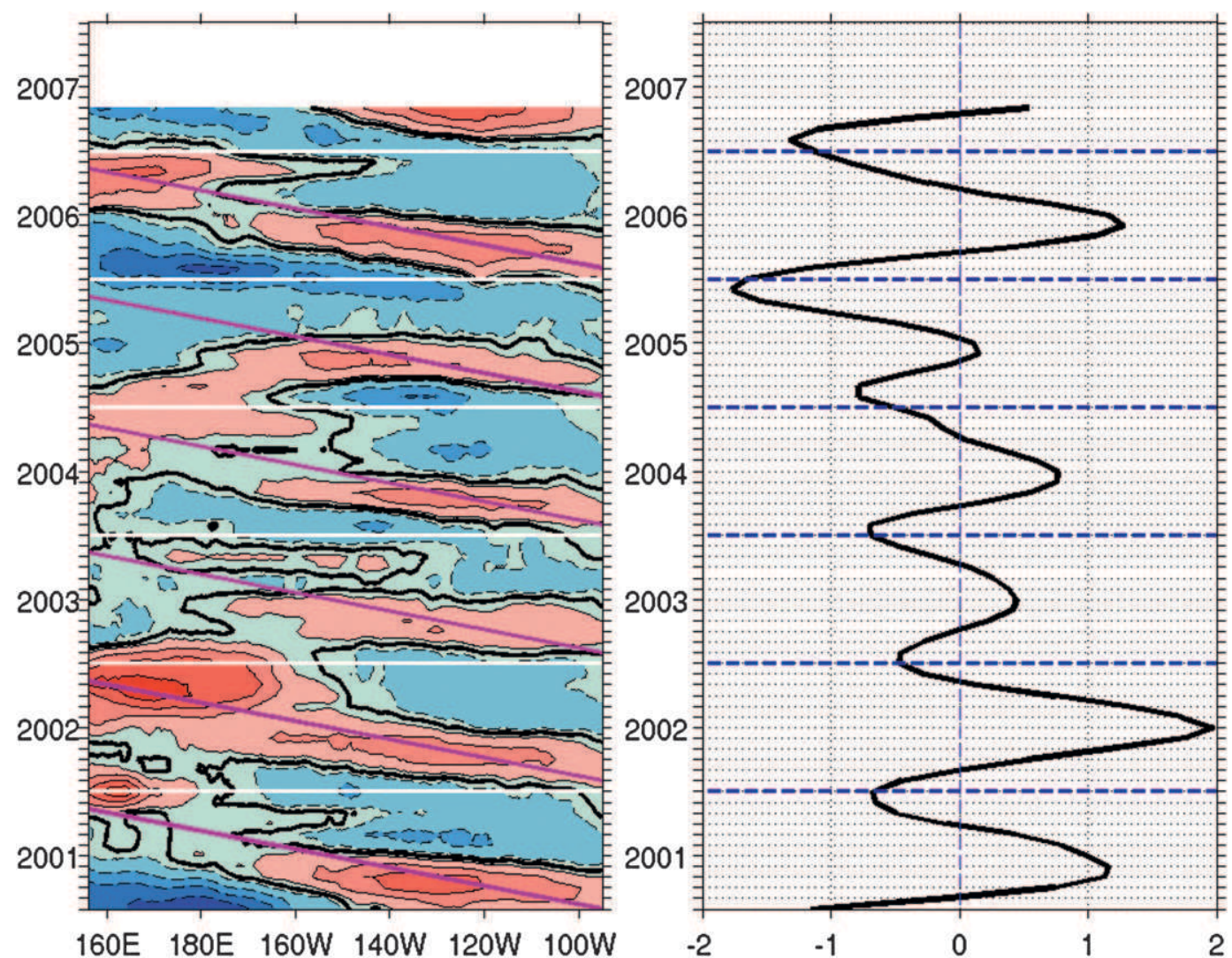

$10^{-2} \mathrm{~N} / \mathrm{m}^{2}$

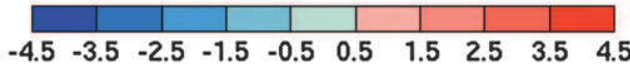

FIG. 15. The interannual variability of monthly averaged zonal wind stress anomalies $\left(10^{-2} \mathrm{~N} \mathrm{~m}^{-2}\right)$ along the equator in the ORCA025 model: (left) the longitude-time distribution and (right) the time evolution of the zonal average along the phase lines of the mean annual cycle. The thick purple continuous lines in the left panel denote the phase lines. The time average has been removed from the zonal wind stress at each longitude. The contour interval is $10^{-2} \mathrm{~N} \mathrm{~m}^{-2}$. The boldface lines denote the zero isolines. The time axis refers to the month when the phase lines cross the middle of the basin $\left(150^{\circ} \mathrm{W}\right)$.

middepth currents for zonal exchanges beneath the thermocline, we computed the distances that Lagrangian particles would cover in middepth due to permanent and annually varying components of the zonal velocity using the above estimates for the amplitudes of annual currents and their annual cycle. Over the course of $1 \mathrm{yr}$, both components lead to comparable Lagrangian displacements on the order of $10^{\circ}-15^{\circ}$ in longitude within the EIC and the L-EIC cores, emphasizing the importance of the annual cycle for water mass displacements beneath the thermocline at annual time scales.

In agreement with the latitudinal structure of meridional mode 1 Rossby waves, these near-equatorial zonal transports are partly compensated for at seasonal time scales by zonal transports of opposite sign on both sides of the equator (approximately within $2^{\circ}$ and $5.5^{\circ}$ in latitude).
Both the EIC and the L-EIC are, therefore, associated with intense horizontal circulations at annual time scales in the equatorial band (between $5.5^{\circ} \mathrm{S}$ and $5.5^{\circ} \mathrm{N}$ ). Hence, the horizontal circulation induces large velocity meridional gradients between equatorial currents and their extraequatorial return counterparts. Such gradients may ultimately generate enhanced lateral mixing below the thermocline that still needs to be quantified. Finally, the amplitudes of the annual cycle for these near-equatorial subthermocline transports in the simulation experience some interannual variability that appears to be related to the interannual modulation of the annual zonal wind stress along the equator. However, the result, based on a short-duration (6 yr) simulation, needs to be confirmed by the analysis of longer-duration simulations. 
An important conclusion of this paper is that the timeaveraged meridional section of zonal currents, presented schematically in Fig. 1, does not account for the subthermocline circulation in the western equatorial Pacific throughout the year. The EIC and the L-EIC are not permanent westward currents but reverse into eastward currents in boreal spring. In addition, large intramonthly and interannual variability in subthermocline zonal transports was found in the model (see Table 1 or Fig. 8). Evidence of such variability can also be found in the sparse observations, for example from the current profiles of 41 cross-equatorial cruises during the Line Islands Profiling Project (LIPP) from March 1982 to June 1983 (Firing 1987, his Fig. 4), showing strong subthermocline currents of opposite direction at $159^{\circ} \mathrm{W}$ in June 1982 and June 1983 (Firing et al. 1998, their Fig. 2). A close look at the LIPP measurements (not shown) suggests that the time variability of subthermocline currents at $159^{\circ} \mathrm{W}$ was predominantly annual in 1982, in agreement with the mean annual cycle computed at this longitude in our model, and that the strong reversal of deep currents in June 1983 was likely to be related to the stronger than usual 1982-83 ENSO event, which led, for instance, to the quasi-disappearance of the EUC in December 1982 (Firing et al. 1983). Further observational and numerical studies would be needed to document and understand the intraseasonal and interannual variability in subthermocline currents. The presence of such variability indicates that a limited number of S-ADCP observations may introduce some biases in the description of the mean/ seasonal zonal currents below the thermocline in the equatorial Pacific.

Despite the low vertical resolution (six points over the full depth range of the EIC and L-EIC) and the moderate horizontal resolution $\left(1 / 4^{\circ}\right)$ of the ORCA025 model, both the amplitude and time variability of the EIC were found to be realistic in the simulation. A twin simulation (not shown), with the same vertical resolution but enhanced horizontal resolution $\left(1 / 12^{\circ}\right)$, revealed no significant changes in the properties and time variability of the EIC and L-EIC, suggesting that these modeled currents did not critically depend on horizontal resolution, as long as the meridional resolution is equal to, or finer than, $14^{\circ}$ in latitude. Additional simulations would be useful in the future in order to determine the sensitivity of our results to the vertical resolution.

Acknowledgments. Model simulations were performed on an SGI computer at Mercator Océan (information online at www.mercator-ocean.fr). Support from Mercator Océan is gratefully acknowledged. Numerous S-ADCP data were freely downloaded from the Joint
Archive for S-ADCP data (JASADCP; information online at http://ilikai.soest.hawaii.edu/sadcp/index.html). These observations are processed and freely made available through the efforts of Gregory Johnson, Julia Hammon, and Eric Firing, with the help of the technicians and crew on the various ships. Comments by Y. Gouriou, E. Firing, and one anonymous reviewer were useful in improving the manuscript.

\section{REFERENCES}

Antonov, J. I., R. A. Locarnini, T. P. Boyer, A. V. Mishonov, and H. E. Garcia, 2006: Salinity. Vol. 2, World Ocean Atlas 2005, NOAA Atlas NESDIS 62, 182 pp.

Arakawa, A., 1966: Computational design for long-term numerical integration of the equations of fluid motion: Two-dimensional incompressible flow. Part I. J. Comput. Phys., 1, 119-143.

_ , and V. R. Lamb, 1981: A potential enstrophy and energy conserving scheme for the shallow water equations. Mon. Wea. Rev., 109, 18-36.

Barnett, T. P., 1983: Interaction of the monsoon and Pacific tradewind system at interannual time scales. Part I: The equatorial zone. Mon. Wea. Rev., 111, 756-773.

Barnier, B., and Coauthors, 2006: Impact of partial steps and momentum advection schemes in a global ocean circulation model at eddy-permitting resolution. Ocean Dyn., 56, 543-567.

Black, A., and C. Black, 1853: Black's General Atlas of the World. A. and C. Black, 70 pp. + maps.

Blanke, B., and P. Delecluse, 1993: Variability of the tropical Atlantic Ocean simulated by a general circulation model with two different mixed-layer physics. J. Phys. Oceanogr., 23, 1363-1388.

Bonjean, F., and G. Lagerloef, 2002: Diagnostic model and analysis of the surface currents in the tropical Pacific Ocean. J. Phys. Oceanogr., 32, 2938-2954.

Brandt, P., and C. Eden, 2005: Annual cycle and interannual variability of the mid-depth tropical Atlantic Ocean. Deep-Sea Res. I, 52, 199-219.

Burkov, V. A., and I. M. Ovchinnikov, 1960: Structure of zonal streams and meridional circulation in the central Pacific during the Northern Hemisphere winter (in Russian). Tr. Instit. Okeanolog. Akad. Nauk. SSSR, 40, 93-107.

Cromwell, T. R., R. B. Montgomery, and E. D. Stroup, 1954: Equatorial undercurrent in Pacific Ocean revealed by new methods. Science, 119, 648-649.

Delcroix, T., and C. Hénin, 1988: Observations of the Equatorial Intermediate Current in the western Pacific Ocean $\left(165^{\circ} \mathrm{E}\right)$. J. Phys. Oceanogr., 18, 363-366.

— and transports in the western tropical Pacific $\left(165^{\circ} \mathrm{E}\right)$. J. Phys. Oceanogr., 17, 2248-2262.

Dewitte, B., and G. Reverdin, 2000: Vertically propagating annual and interannual variability in an OGCM simulation of the tropical Pacific Ocean in 1985-94. J. Phys. Oceanogr., 30, 1562-1581.

Eldin, G., A. Morlière, and G. Reverdin, 1992: Acoustic Doppler current profiling along the Pacific equator from $95^{\circ} \mathrm{W}$ to $165^{\circ} \mathrm{E}$. Geophys. Res. Lett., 19, 913-916.

Eriksen, C. C., 1981: Deep currents and their interpretation as equatorial waves in the western Pacific Ocean. J. Phys. Oceanogr., 11, 48-70.

Firing, E., 1987: Deep zonal currents in the central equatorial Pacific. J. Mar. Res., 45, 791-812. 
1988: Shallow equatorial jets. J. Geophys. Res., 93, 9213-9222.

_ , R. Lukas, J. Sadler, and K. Wyrtki, 1983: Equatorial undercurrent disappears during 1982-83 El Niño. Science, 222, 1121-1123.

_ S. E. Wijfells, and P. Hacker, 1998: Equatorial subthermocline currents across the Pacific. J. Geophys. Res., 103, 21 413-21 423.

Ganachaud, A., G. Eldin, R. Chuchla, M. Rodier, A. Lapetite, F. Gallois, and C. Dupouy, 2006: Rapport de la mission FRONTALIS 2 à bord du Navire Océanographique l'Alis du 2 au 30 avril 2004. Rapports de Missions, Sciences de la Mer, Océanographie Physique, Vol. 8, Centre IRD de Nouméa, 185 pp.

Gent, P. R., and J. R. Luyten, 1985: How much energy propagates vertically in the equatorial oceans? J. Phys. Oceanogr., 15, 997-1007.

Goosse, H., J.-M. Campin, E. Deleersnijder, T. Fichefet, P.-P. Mathieu, M. A. M. Maqueda, and B. Tartinville, 2001: Description of the CLIO model version 3.0. Institut d'Astronomie et de Géophysique Georges Lemaitre Science Rep. 2002/3, 49 pp.

Gouriou, Y., and J. M. Toole, 1993: Mean circulation of the upper layers of the western equatorial Pacific Ocean. J. Geophys. Res., 98, 22 495-22 520.

_ - T. Delcroix, and G. Eldin, 2006: Upper and intermediate circulation in the western equatorial Pacific Ocean in October 1999 and April 2000. Geophys. Res. Lett., 33, L10603, doi:10.1029/ 2006GL025941.

Halpern, D. A., 1980: A Pacific equatorial temperature section from $172^{\circ} \mathrm{E}$ to $110^{\circ} \mathrm{W}$ during winter and spring 1979. Deep-Sea Res., 27, 931-940.

Hayes, S. P., J. M. Toole, and L. J. Mangum, 1983: Water-mass and transport variability at $110^{\circ} \mathrm{W}$ in the equatorial Pacific. J. Phys. Oceanogr., 13, 153-168.

Hisard, P., and P. Rual, 1970: Courant equatorial intermédiaire de l'Océan Pacifique et contre-courants adjacents. Cah. ORSTOM Sér. Océanogr., 8, 21-45.

Johnson, G. C., B. M. Sloyan, W. S. Kessler, and K. E. McTaggart, 2002: Direct measurements of upper ocean currents and water properties across the tropical Pacific during the 1990s. Prog. Oceanogr., 52, 31-61.

Kessler, W. S., and B. A. Taft, 1987: Dynamic heights and zonal geostrophic transports in the central tropical Pacific during 1979-1984. J. Phys. Oceanogr., 17, 97-122.

— wave in the subthermocline equatorial Pacific. J. Phys. Oce anogr., 23, 1192-1207.

Knauss, J. A., 1963: Equatorial current systems. The Sea, M. N. Hill, Ed., The Composition of Sea-Water and Comparative and Descriptive Oceanography, Vol. 2, John Wiley and Sons, $235-252$.
Leetmaa, A., and P. F. Spain, 1981: Results from a velocity transect along the equator from $125^{\circ}$ to $159^{\circ} \mathrm{W}$. J. Phys. Oceanogr., 11, $1030-1033$.

Locarnini, R. A., A. V. Mishonov, J. I. Antonov, T. P. Boyer, and H. E. Garcia, 2006: Temperature. Vol. 1, World Ocean Atlas 2005, NOAA Atlas NESDIS 61, 182 pp.

Lukas, R., and E. Firing, 1985: The annual Rossby wave in the central equatorial Pacific Ocean. J. Phys. Oceanogr., 15, 55-67.

Madec, G., 2008: NEMO ocean engine. Institut Pierre-Simon Laplace Note du Pôle de Modélisation 27, 205 pp.

Maes, C., and Coauthors, 2006: Rapports de la mission FRONTALIS 3 à bord du N.O Alis du 22 avril au 19 mai 2005, 22S-2N, 161E172E. Rapports de Mission, Sciences de la Mer, Océanographie Physique, Vol. 20, Centre IRD de Nouméa, 167 pp.

Magnier, Y., H. Rotschi, P. Rual, and C. Colin, 1973: Equatorial circulation in the western Pacific $\left(170^{\circ} \mathrm{E}\right)$. Prog. Oceanogr., 6, $29-46$.

Picaut, J., and R. Tournier, 1991: Monitoring the 1979-1985 equatorial Pacific current transports with expendable bathythermograph data. J. Geophys. Res., 96, 3263-3277.

Puls, C., 1895: Oberflächentemperaturen und Stromungsverhaltnisse des Äquatorialgurtels des Stillen Ozeans. Dtsch. Arch. Seewarte, 18, $1-38$.

Reid, J. L., 1961: On the geostrophic flow at the surface of the Pacific Ocean with respect to the 1000-db surface. Tellus, 13, 489-502.

Reverdin, G., C. Frankignoul, E. Kestenare, and M. J. McPhaden, 1994: Seasonal variability in the surface currents of the equatorial Pacific. J. Geophys. Res., 99, 20 323-20 344.

Rothstein, L. M., D. W. Moore, and J. P. McCreary, 1985: Interior reflections of a periodically forced equatorial Kelvin wave. J. Phys. Oceanogr., 15, 985-996.

Roullet, G., and G. Madec, 2000: Salt conservation, free surface and varying volume: new formulation for ocean GCMs. J. Geophys. Res., 105, 23 927-23 942.

Rowe, G. D., E. Firing, and G. C. Johnson, 2000: Pacific equatorial subsurface countercurrent velocity, transport, and potential vorticity. J. Phys. Oceanogr., 30, 1172-1187.

Sudre, J., and R. A. Morrow, 2008: Global surface currents: highresolution product for investigating ocean dynamics. Ocean Dyn., 58, 101-118.

Sverdrup, H., M. Johnson, and R. Fleming, 1942: The Oceans: Their Physics, Chemistry and General Biology. Prentice-Hall, 1087 pp.

Thierry, V., A. M. Treguier, and H. Mercier, 2004: Numerical study of the annual and semi-annual fluctuations in the deep equatorial Atlantic Ocean. Ocean Modell., 6, 1-30.

Wyrtki, K., 1974: Sea level and the seasonal fluctuations of the equatorial currents in the western Pacific. J. Phys. Oceanogr., 4, 91-103.

, and B. Kilonsky, 1984: Mean water and current structure during the Hawaii-to-Tahiti. J. Phys. Oceanogr., 14, 242-254. 